\title{
Client data files and auditor skepticism: How do "dirty" files influence auditors' skeptical judgments and actions?
}

\begin{abstract}
Auditors receive an abundance of client-prepared data files when performing audit work. With today's increasingly data-rich environment, these files are likely becoming even more challenging for auditors to cognitively process. Specifically, these data files may have characteristics (e.g., contain errors or irrelevant information; aka "dirty" files) that could challenge their ease of use and interpretation (i.e., processing fluency). Depending on this ease, auditors may view these files as relatively less reliable and trustworthy, resulting in skeptical judgments and actions that are sometimes excessive. This paper reports two experiments examining whether two features of the data files, the presence of minor errors (absent or present) and information load (low or high), influence auditors' processing fluency, skeptical judgments, and actions. While minor errors should raise auditors' concerns, greater information load should not. However, we find the lowest processing fluency and highest skeptical judgments and actions when minor errors are present and information load is higher. Our study contributes to the literature by presenting an alternative issue to those raised by regulators (i.e., too much skepticism rather than too little) that can occur when auditors struggle to interpret large amounts of data. From a practical perspective, while access to increased amounts of client data may have benefits, audit firms and clients need to be wary of the potential for wasted time that could create inefficiencies that may affect audit quality.
\end{abstract}

Key Words: Client-prepared Data Files; Processing Fluency; Skeptical Judgments and Actions; Eye Tracking 


\section{Introduction}

Professional skepticism is essential to audit quality, and exercising an appropriate level of skepticism is of great concern to regulators, practitioners, and academics (e.g., PCAOB 2012; Hurtt et al. 2013; KPMG 2017). However, maintaining an appropriate level of skepticism continues to be a perplexing and challenging task for auditors. While not having enough skepticism is clearly problematic, and a major concern of regulators (e.g., Franzel 2013; IFIAR 2018), auditors' time and resources are limited. Therefore, spending too much time on areas that should have been evaluated as less risky puts increased time and budget pressure on auditors to find areas where they can do less work and/or engage in reduced audit quality acts (e.g., Coram et al. 2004). This weighing of efficiency and effectiveness is likely to be further heightened during the busy season time crunch associated with accelerated filers (Lambert et al. 2017). Much of the extant literature focuses on investigating factors that may inappropriately hinder skepticism (e.g., the outcome effect, Brazel et al. (2016)) or mechanisms that can encourage or improve skepticism (e.g., construal level, Backof et al. (2018); incentives, Brazel et al. (2018)). We extend this literature by examining factors that may cause auditors' skepticism to be excessive in certain areas (e.g., collecting too much evidence in a low risk area), which may unnecessarily consume auditors' limited resources.

Client-prepared data files (e.g., detailed listings, account schedules) are a key source of information that may affect an auditor's level of skepticism when conducting audit work (Nelson 2009; Hurtt et al. 2013). Importantly, characteristics of these files (e.g., irrelevant information or errors, variations in format, level of organization; aka “dirty” files) may influence auditors' ease of use and interpretation of information contained in the files that could result in excessive skepticism. This issue may be particularly problematic in today's data-rich environment, where 
auditors' abilities to cognitively process information may be hindered by the quantity of data they encounter (Brown-Liburd et al. 2015; Rose et al. 2017). Specifically, we investigate whether two prevalent features of client-prepared data files, the presence of minor errors (absent or present) and information load (low or high), influence the ease with which client information can be interpreted (i.e., processing fluency), as well as the effects on auditors' skeptical judgments and actions. ${ }^{1}$

We draw from literature on cognitive processing to predict that auditors' processing fluency is affected by the degree to which client-prepared data files are "dirty". Processing fluency, in turn, may affect auditors' skeptical judgments and actions. Minor errors should naturally raise auditor's concerns regarding the client's competency (e.g., Luippold et al. 2015). In addition to this logical response to errors, research indicates that features such as mistakes, errors, or factors affecting the legibility of information, may interrupt the ease with which information can be interpreted regardless of their relevance to the underlying content of the information (e.g., Roussey and Piolat 2008). The resulting decrease in processing fluency affects individuals at a subconscious level, causing individuals to view difficult to process information as less reliable or truthful than information that is easier to process (e.g., Reber and Schwarz 1999; Rennekamp 2012). The presence of error-free information that is irrelevant to the decision at hand should not impact auditors' assessments. However, we predict that, when combined with information containing minor errors, an increase in information load further inhibits auditors' processing fluency, exacerbating auditors' tendency to perceive the information as unreliable and intensifying the saliency of errors within relevant information. Thus, we anticipate that the extent to which an

\footnotetext{
${ }^{1}$ Processing fluency refers to the ease with which individuals can interpret and understand information (Johnston et al. 1985). Prior research shows that feelings of greater processing fluency are subconsciously treated by individuals as a heuristic cue that information can be relied upon in making related judgments (Shah and Oppenheimer 2007; Rennekamp 2012). Skeptical judgment occurs when auditors recognize an issue may exist and that more work may be needed. Skeptical action occurs when auditors change their behavior to respond to the identified issue (Hurtt et al. 2013).
} 
auditor's skeptical judgments and actions increase when errors are present is greater when information load is higher versus when it is lower.

We test our predictions using two controlled $2 \times 2$ between-subjects experiments. In both experiments, participants' task is to examine a client-prepared accounts receivable detailed listing. Participants assess whether they would update the likelihood of misstatement for the account and indicate if an adjustment to the sample size is needed. Experiment 1 uses 37 undergraduate and graduate auditing students and Experiment 2 uses 97 accounting professionals with audit experience. We manipulate minor errors (absent or present) and information load (low or high). In Experiment 1, we assess participants' processing fluency using an eye tracker that captures participants' number of fixations while viewing one of the four accounts receivable treatments. ${ }^{2}$ Experiment 2 carries the task over to professionals and assesses participants'skeptical judgments (assessment of the likelihood of account misstatement) and actions (adjustment to sample size).

The results of both studies provide evidence that certain features of client-prepared data influence individuals' ease of processing information, as well as their skeptical judgments and actions. Results of Experiment 1 reveal a significant main effect for minor errors, with participants having decreased processing fluency (greater number of fixations; e.g., Deng et al. 2016) when minor errors are present versus absent. Results also provide support for a significant interaction between minor errors and information load, such that higher information load decreases processing fluency more when minor errors are present. In addition, using a path analysis, we find that features of the client-prepared data file (i.e., minor errors and information load) influence individuals' processing fluency, which in turn affects auditors' skeptical judgments and actions. Specifically,

\footnotetext{
${ }^{2}$ Because we use an eye tracker that requires participants to be present in our university lab, we could not obtain professional participants. Rennekamp (2018) recommends being creative in the use of participants, such that testing underlying theory with student participants can be sufficient when context-specific outcomes are tested with participants from the population of interest.
} 
as participants' ease of interpreting the client-prepared information decreases, their skeptical judgment increases, and in turn, their skeptical actions increase.

Experiment 2 results indicate a main effect for minor errors, where both account misstatement likelihood and sample size increase when minor errors are present. Our results also support our predicted pattern of results with higher information load increasing both misstatement likelihood and sample size when errors are present versus absent. However, simple effects tests indicate a significant difference for sample size (i.e., skeptical action), but not misstatement likelihood (i.e., skeptical judgment). The significant effect of information load on skeptical action is important, as the action impacts audit efficiency and thus leads to the potential need to compensate for this inefficiency in other areas of the audit. Finally, post-experiment questions indicate that professional participants often encounter "dirty" data files in audit practice, and many agree that these files are likely to influence their level of professional skepticism.

Our study contributes to academic literature in a number of ways. First, we build on prior skepticism literature by examining how a pervasive feature within the audit environment (i.e., variability in client-prepared data file characteristics) can influence auditors' processing ease and resulting skeptical judgments and actions, a topic not previously considered by researchers (Nelson 2009; Hurtt et al. 2013). Importantly, we also address the call for researchers to empirically measure the underlying cognitive processes of individuals when they are making skeptical judgments and decisions (Nolder and Kadous 2018). Nolder and Kadous (2018) highlight the importance of understanding the cognitive processes underlying an individual's skeptical judgments and actions, but they indicate that research on professional skepticism often omits examination of such processes. Our study highlights the use of a novel research tool (an eye tracker) to assess a cognitive measure (processing fluency) that audit researchers may use when 
assessing professional skepticism or other important auditor judgments and decisions (see Lynch and Andiola 2018). Finally, we contribute to broader decision theory and eye-tracking literature by examining the cognitive processing underlying decisions in a professional context that organizational behavior researchers indicate is understudied (e.g., Orquin and Loose 2013; Meißner and Oll 2019).

Our findings also have important practical implications for the auditing profession. First, with the push for more and more data from audit clients, firms need to be cautious about how their audit teams use and evaluate this client-prepared information. Our results suggest that receiving files with unnecessary information from the client (a very common practice), when minor errors are present, leads to excessive skepticism. This excessive skepticism may reduce audit quality by creating inefficiencies that result in effectiveness issues in other audit areas. Specifically, time is an extremely limited resource for auditors, and thus spending time on one area naturally limits the time the auditor can spend on another. In addition, audit clients should be aware that certain features of client-prepared data files might unduly raise auditors' concerns. Client personnel may think providing an unedited readily-available file is efficient, or they may reason that providing excessive information to auditors could be a good tactic to hide the "needle in the haystack" (Luippold et al. 2015). However, our results suggest that there could be negative repercussions that may result in more work for client personnel, such as having to gather and provide more evidence for a larger sample, when the file gives rise for concern due to errors and contains too much information for auditors to effectively process.

The remainder of this paper proceeds as follows. Section 2 develops our theory and hypotheses. Sections 3 and 4 describe methods and results, respectively, for our first experiment. Section 5 presents methods and results of our second experiment. Section 6 concludes. 


\section{Background and hypothesis development}

\section{Background on client-prepared data files}

Auditing standards require auditors to gather sufficient and appropriate evidence to support their audit conclusions (PCAOB 2010), and regulators emphasize the importance of maintaining appropriate levels of professional skepticism (PCAOB 2012). To this end, auditors typically request a significant amount of prepared by client documents (often referred to in practice as PBCs) that include both data files and supporting documentation (e.g., purchase orders, sales invoices, contracts). Client-prepared data files include trial balances, detailed account listings, and specific account schedules and reconciliations. These files can come in a variety of forms (e.g., Excel files, PDFs) and may vary significantly in their ease of use and interpretation (e.g., files can be disorganized, contain irrelevant or unnecessary information, contain minor or major errors).

While prior audit literature indicates that characteristics of an audit task and interactions with the client can influence auditors' judgments and decisions (Nelson and Tan 2005; Fukukawa and Mock 2011; Bennett and Hatfield 2013), research directly investigating how specific features of client-prepared data files can impact auditors' judgments and decisions is more limited. Yet psychology research suggests that individuals' judgments may be influenced by both information content and the cognitive experience of processing that information (e.g., Tversky and Kahneman 1973; Schwarz et al. 1991). Moreover, as the amount of data available to auditors (e.g., Big Data) continues to grow, auditors are likely to be constantly challenged to evaluate and cognitively process more and more data (Brown-Liburd et al. 2015).

In this study, we examine whether two prevalent features of client-prepared data files, the presence of minor errors (absent or present) and information load (low or high), influence the ease with which client information can be interpreted (i.e., processing fluency), as well as the effects on auditors' skeptical judgments and actions. Figure 1 illustrates our proposed theoretical model. 
While some evidence exists that individually errors or information load can influence auditors' judgments during audit work (e.g., Simnett 1996; Luippold et al. 2015), no study examines the combination of these two factors. In addition, no study investigates how characteristics of clientprepared data files affect an individual's underlying cognitive processing of such information.

\section{[INSERT FIGURE 1]}

\section{The effects of client-prepared data files with minor errors}

Processing fluency refers to the ease with which individuals can process information. This feeling of ease is a subjective experience that subconsciously influences individuals' responses to information (Alter and Oppenheimer 2009). Processing fluency often affects judgments independent of the content of the information being processed (Schwarz et al. 1991; Alter and Oppenheimer 2009). Prior literature finds that factors that affect processing fluency include elements that influence the way in which the information is presented (visual, linguistic, and semantic elements) and presentation methods that facilitate memory or retrieval (see Alter and Oppenheimer 2009 for a review).

Individuals respond to fluency by implementing theories about what processing ease implies in a given context (Skurnik et al. 2000; Schwarz 2004). These theories, referred to as "naïve theories" in the literature, may or may not be consistent with the conclusions that would be drawn based on the actual information content. For example, circumstances that enhance the ease of processing information are found to increase feelings that the information is familiar (e.g., Jacoby and Whitehouse 1989; Whittlesea et al. 1990) and that the information is reliable or true (Reber and Schwarz 1999; Reber et al. 2004; Unkelbach 2007; Hansen et al. 2008; Rennekamp 2012). Rennekamp (2012) finds that a more readable financial performance disclosure leads to increased processing fluency, which in turn acts as a subconscious heuristic cue that influences nonprofessional investors' reliance on financial disclosures. Thus, nonprofessional investors 
subconsciously formed a judgment based on their perceptions of processing fluency, rather than on the actual content of the disclosure's truthfulness.

In the audit context, auditors must assess client-prepared information that may contain minor or major errors. Such errors in client-prepared documents may legitimately convey information that is relevant to the auditors' decisions, or they may simply be unimportant distractions. In either case, errors may decrease auditors' processing fluency by introducing visual and linguistic interruptions. For example, Roussey and Piolat (2008) find that participants exert more critical reading effort in a text revision task when the text contains spelling and syntax errors. Thus, when client information contains mistakes or errors, it likely becomes more difficult to process, as errors may inhibit the visual ease of processing the content and the linguistic flow of the text. We therefore hypothesize that:

HYPOTHESIS 1a. Auditors' processing fluency decreases when minor errors are present versus when they are absent.

In non-audit contexts, research indicates that suboptimal visual elements and linguistic features that interrupt the flow of a written passage are negatively associated with perceptions of information truthfulness (Brennan and Williams 1995; Reber and Schwarz 1999; McGlone and Tofighbakhsh 2000). For example, prior literature finds that the visual ease of processing information may be affected by font style (Alter et al. 2007; Novemsky et al. 2007), text clarity or visibility (Reber et al. 1998; Reber and Schwarz 1999), or the length of time information is visible (Winkielman and Cacioppo 2001). Consistent with these contexts, the decreased processing fluency introduced by errors may lead auditors to use this as a simplifying heuristic to conclude that client documents containing errors are less truthful or less reliable (Schwarz et al. 1991; Alter and Oppenheimer 2009). 
Further, auditors' training and experience may provide additional reason to associate minor errors themselves with a lack of reliability (Luippold et al. 2015). When present, such errors may rightfully raise questions about the client's competency. The fact that the client prepared and/or reviewed the data but was unable or did little to detect or clean up the mistakes may send a negative signal about the specific account or other areas of the financial statements.

If minor errors in client-prepared data files interrupt the ease with which the information is processed, the interruptions in cognitive processing will likely decrease feelings of reliability in general, but also draw further attention to the errors that make auditors' question the client's competency. Thus, minor errors are likely to trigger more skeptical judgments and actions. This leads to the following hypothesis:

HYPOTHESIS 1b. Auditors' skeptical judgments and actions increase when minor errors are present versus when they are absent.

\section{The interactive effect of client-prepared data files with minor errors and information load}

In addition to minor errors, client-prepared data may vary in the quantity of information the auditor must cognitively process. For example, client personnel may export and provide the auditors with transaction information from their accounting system in a preprogrammed format to minimize their own workload, without considering whether all of the information is needed by the auditor. Information load may be particularly problematic in today's audit environment, due to the increasing amounts of data clients provide and that auditors are able to access (Brown-Liburd et al. 2015; Rose et al. 2017). In general, too much information can confuse an individual, lead to longer decision times, and negatively affect their decision-making (Jacoby 1984; Schick et al. 1990; Eppler and Mengis 2003). Similarly, accountants find it difficult to process information and make decisions when they encounter large amounts of information (e.g., Casey 1980; Iselin 1988; Chewning and Harrell 1990; Stocks and Harrell 1995) and auditors suffer from low quality 
judgments when faced with excessive information (e.g., Simnett 1996; Alles et al. 2008). In addition, accounting studies that examine irrelevant information, a related characteristic of information load, find that it can lead to a dilution effect where decision quality is reduced due to irrelevant information inhibiting an individual's ability to identify relevant information (e.g., Hackenbrack 1992; Hoffman and Patton 1997). As such, information load may distract auditors from attending to errors in client-provided data, inhibiting their processing fluency and diluting the effect that errors may otherwise have on triggering skeptical judgments and actions. However, auditors routinely deal with large quantities of complex information, and their training and experience may make them less susceptible than other individuals to the potential ill effects of information load.

Importantly, research indicates that not only the amount of information (quantitative aspect) that needs to be assessed is crucial, but also the characteristics (qualitative aspect) of the information (Keller and Staelin 1987; Schneider 1987; Iselin 1993). For instance, Schneider (1987) indicates that information attributes such as ambiguity or complexity can also influence ease and interpretation of information. When client-prepared data files contain no errors, increased information load may not negatively affect auditors' assessments of the data because there are no interruptions to inhibit the ease with which the information is processed. ${ }^{3}$

Alternatively, the combination of higher information load (i.e., a quantitative aspect) and minor errors (i.e., a qualitative aspect) may act together to significantly decrease individuals' abilities to interpret the information (Eppler and Mengis 2003). Errors serve as interruptions that reduce processing fluency across the client-prepared data file. Prior literature indicates that reduced processing fluency negatively influences judgments of information quality independent

\footnotetext{
${ }^{3}$ For our purposes, we focus on information load that is free of any contextual factors that might provide meaningful or valueadded content to auditors.
} 
of the information's underlying content (Alter and Oppenheimer 2009; Schwarz et al. 1991). This implies that when processing fluency is interrupted by errors, which are meaningful signals within relevant information, auditors' unconscious interpretation of the irrelevant information may also be affected.

In addition, psychology research on halo effects suggests that evaluators apply a simplifying heuristic that rates new or additional attributes according to a global effect rather than discriminating carefully between each attribute and evaluating each attribute independently (Nisbett and Wilson 1977; Murphy et al. 1993). If minor errors reduce auditors' processing fluency and make them question the client's competence, these negative impressions may leave a "halo" that results in evaluating other attributes (e.g., other unnecessary information) in a similar negative manner (e.g., James 2003; Gramling et al. 2010). In other words, when errors are present in relevant information auditors may be prone to interpret error-free irrelevant information as untruthful or unreliable (i.e., a halo effect) and exert undue effort trying to process this additional information. Thus, rather than diluting the effect of errors that studies on irrelevant information suggest may occur, we predict that higher information load will act to exacerbate the processing fluency effects of the presence of minor errors. Figure 2 illustrates the pattern of our predicted results. We hypothesize that:

HYPOTHESIS 2a. The extent to which an auditor's processing fluency decreases when minor errors are present (versus absent) is greater when information load is higher versus when it is lower.

\section{[INSERT FIGURE 2]}

Because auditors' abilities to process information may be further interrupted when both minor errors are present and information load is high, this is likely to lead to even greater feelings of unease that the information is unreliable despite the additional information providing no information value (e.g., Reber and Schwarz 1999; Rennekamp 2012). These increased feelings of 
untrustworthiness may lead to a halo effect that makes auditors excessively skeptical, above that warranted by rational logic. Importantly, because auditors are trained and continuously advised to be skeptical, when auditors have both a "trigger" (like minor errors) and other factors that reduce their ability to cognitively process the information quickly (i.e., high information load) their decisions may be based more on a mindset of presumptive doubt than a more neutral perspective (Quadackers et al. 2014). Thus, we anticipate that the extent to which an auditor's skeptical judgments and actions increase when errors are present is greater when information load is higher versus when it is lower. This leads to our final hypothesis:

HYPOTHESIS $2 \mathrm{~b}$. The extent to which an auditor's skeptical judgments and actions increase when minor errors are present (versus absent) is greater when information load is higher versus when it is lower.

\section{Experiment 1 method}

To investigate our hypotheses, we conduct two experiments. ${ }^{4}$ The first experiment uses a student participant pool to examine the effects of minor errors and information load on an individual's processing fluency, testing Hypotheses 1a and 2a. Following these tests, we perform a path analysis to examine the causal role an individual's processing fluency plays on skeptical judgments and actions in order to provide empirical evidence for our underlying theoretical prediction for our results in Experiment 2. The second experiment uses a professional participant pool to examine the effects of minor errors and information load on auditors' skeptical judgments and actions, testing Hypotheses $1 \mathrm{~b}$ and $2 \mathrm{~b}$.

\section{Experimental design and eye tracker}

Experiment 1 uses a 2 x 2 design in which we manipulate between subjects the presence of minor errors (absent versus present) and information load (low versus high) in a client-prepared

\footnotetext{
${ }^{4}$ We obtained Institutional Review Board (IRB) approval separately for each experiment.
} 
data file. Processing fluency, how easily information can be processed (also referred to as perceptual fluency in the eye-tracking literature, see Alter and Oppenheimer 2009; Rennekamp 2012; Lynch and Andiola 2018), was measured using an eye tracker. We discuss this variable in detail in our dependent variable section. Eye trackers record eye movements during a task that can provide understanding of the underlying cognitive processes that trigger an assortment of behaviors (Holmqvist et al. 2011; Ashby et al. 2016). Tracking and analyzing eye movements has helped researchers examine human behavior across a number of disciplines, including psychology, organizational behavior, and information systems (Dimoka et al. 2012; Orquin and Loose 2013; Meißner and Oll 2019). The use of eye tracking in accounting is still in its infancy (Lynch and Andiola 2018), but there is emerging evidence of its' potential (e.g., Chen et al. 2016; Dalla Via et al. 2018; Sirois et al. 2018). See Lynch and Andiola (2018) for an in-depth discussion of applying eye tracking to behavioral accounting research.

We used a Tobii X2-60 remote eye tracker that was desktop-mounted in a lab setting at the researchers' university. Recordings are taken with a frequency of $60 \mathrm{~Hz}$. One of the benefits of the Tobii X2-60 eye tracker is that it is unobtrusive; participants can sit comfortably in front of the computer without having to wear special headgear or maintain a specific distance from the monitor. When participants first entered the eye-tracking lab, members of the research team explained the specifics of the study and obtained consent. Then each participant was given a brief introduction to eye-tracking technology and how to use the computer before beginning the experimental task. Prior to the start of the task, each participant was calibrated to the eye-tracking software. The calibration process required them to visually follow a bouncing ball around the computer screen with their eyes. Following calibration, participants accessed the audit case materials and began the task, all while their gaze behaviors were recorded. 


\section{Participants}

Senior undergraduate and graduate students currently enrolled in auditing courses at a large southeastern university were recruited as participants for this study. Participants were recruited through an email request sent by their audit professor and were told they would receive extra credit points as compensation for participation. The email included a link to Sona Systems, an online scheduling management software that allowed them to schedule a convenient lab time. Forty-six auditing students completed the experiment. ${ }^{5}$ Participants were randomly assigned to one of the four treatment conditions based on the order in which participants arrived at the lab. ${ }^{6}$ On average, participants had one year of accounting experience and six years of other work experience. Seventy-nine percent of participants were undergraduate students, and 51 percent were male. We also measured trait-level professional skepticism using the Hurtt scale (Hurtt 2010). Student participants' skepticism was 76.8 on average (100-point scale), similar to other studies using accounting students (e.g., mean $=73.1$ in Popova $(2013)$; mean $=74.3$ in Peytcheva $(2014)){ }^{7}$

\section{Task and procedures}

The case scenario had participants assume the role of an auditor performing the accounts receivable portion of an audit of a hypothetical company, described as a mid-sized public company specializing in the production of plastic shaped bottles. ${ }^{8}$ The case scenario indicated that the audit team assessed the inherent risk for the account as high and the control risk for the account as low. Thus, the overall risk of material misstatement for the account was described as moderate. The background materials told participants that the initial estimate of the likelihood of accounts

\footnotetext{
${ }^{5}$ Forty-seven participants consented to participate, but one could not be calibrated due to heavy eye-makeup.

${ }^{6}$ Small cell sizes are common in eye-tracking studies (Dalla Via et al. 2018; Meißner and Oll 2019). Our average cell size is consistent with the minimum recommendations suggested by Holmqvist et al. (2011).

${ }^{7}$ Participants' trait-level skepticism was not significantly different between conditions and not significant when included as a covariate in our hypothesis tests.

${ }^{8}$ The materials were adapted from a teaching case by Andiola et al. (2018).
} 
receivable being misstated is 20 percent and ten items from the accounts receivable detailed listing were chosen to be tested in the prior year. Participants were tasked with reviewing the client data file, providing an updated likelihood of the account being misstated and selecting the number of items they would like to test.

Before proceeding to review the client data file, participants were required to pass a knowledge check to verify they were aware of the initial misstatement likelihood and the prior year sample size. The first question asked them "What was your initial estimate of the likelihood of accounts receivable being misstated?" The second question asked them "In prior years, how many items did your firm select to sample?" In order to proceed, participants had to select "20 percent" for the first question and "10 items" for the second question. Participants were allowed multiple attempts at selecting the correct answer.

The next screen contained a reminder of the participants' task requirements. This was followed by the client data file screen, which contained the accounts receivable detailed listing and the manipulations for the four treatment conditions. After viewing the data file at their own pace, they continued to the next section where they clicked on a link that connected them to a Qualtrics survey. Participants first entered their responses to specific case questions, and then they completed a post-experimental survey.

\section{Independent variables}

The first independent variable is the presence of minor errors. This variable was manipulated at two levels (absent versus present). ${ }^{9}$ Participants assigned to the minor errors absent condition were presented with a client document that was free from errors: the total account balance tied to the balance sheet, there were no minor typographical errors in the information, and

\footnotetext{
${ }^{9}$ In order to determine the appropriate number and type of errors, variations of the potential instrument were pilot tested with 40 undergraduate auditing students.
} 
the information was complete. In the minor errors present condition, participants were presented with client-prepared audit evidence that contained five minor errors: the total account balance did not tie to the balance sheet, there were minor typographical errors, and there were blank spaces indicating that pieces of the information were potentially missing.

The second independent variable is information load. This variable was manipulated at two levels (low versus high). Participants assigned to the low information load condition were presented with a client document that had only necessary information. This condition showed an accounts receivable listing with columns for the customer name, invoice number, invoice date, and invoice amount. Alternatively, participants assigned to the high information load condition were presented with an accounts receivable listing that contained additional columns with other irrelevant customer information. These columns contained information on the state the customer is located in, the phone number of the customer, the name of the customer's contact, the name of the items sold and the number, as well as the skew code. ${ }^{10}$ Appendix A presents the four screens participants viewed depending on their assigned treatment condition.

\section{Dependent variables}

The dependent variable of interest in Experiment 1 is participants' processing fluency when examining the client data file. To measure processing fluency, we use an eye tracker to capture the total number of participants' fixations on the client data file screen (i.e., the number of times gaze was held within the defined area of interest) (Lynch and Andiola 2018). Research suggests that when individuals are having difficulty interpreting information, they have a higher number of fixations (Just and Carpenter 1980; Ehmke and Wilson 2007; Holmqvist and Andersson 2017). To analyze the eye tracking data, we use the Tobii Pro Studio software package, developed by the

\footnotetext{
${ }^{10}$ Three auditors with public accounting experience verified that the information load manipulation accurately depicts examples of unnecessary information that auditors encounter in practice.
} 
creators of Tobii X2-60 eye tracking devices. We use the IV-T fixation filter (Tobii AB 2016), a commonly used filter reported in the eye tracking literature that uses Tobii technology (e.g., Fehrenbacher et al. 2018). ${ }^{11}$ In our study, a fixation is recorded when participants spend at least $60 \mathrm{~ms}$ holding their gaze on a particular spot. We set this threshold relatively low because short fixations are commonly present during reading, and our key area of interest contains textual information (Rayner 2009; Glöckner et al. 2012; Djamasbi 2014). The velocity threshold is set at 30 visual degrees per second. ${ }^{12}$

In addition, we assess participants' skeptical judgments and actions in order to examine whether processing fluency is the underlying mechanism driving the relationship between characteristics of client-prepared data files and skepticism. To assess participants' skeptical judgment we ask them about the likelihood of an account misstatement (Payne and Ramsay 2005; Nolder and Kadous 2018). Participants were given an initial estimate of the likelihood that accounts receivable may be misstated (20 percent). After reviewing the client data file, participants were asked to provide an updated assessment of the likelihood that the account could be materially misstated on a scale ranging from 0 percent (Low likelihood) to 100 percent (High likelihood). The measure of skeptical judgment is the difference between the initial estimate and the participant's assessment of misstatement likelihood after reviewing the data file.

\footnotetext{
${ }^{11}$ The process of fixation identification is supported by mathematical algorithms and statistical analysis approaches available in Tobii Pro Studio by selecting one of the fixation filters built in to the software. The filters determine how the raw data reflecting eye fixations will be analyzed by the software. Therefore, this choice is important for properly capturing eye movements (Tobii AB 2016). The filters determine the start and the end points of both fixations and saccades. The I-VT filter is based on eyes' angular velocity and operates on eye movement data. As a result, the data is independent of screen size, screen resolution, and the distance between the stimulus and eyes (Tobii AB 2016).

12 Since the eye is never completely still and experiences micro-saccades (Holmqvist et al. 2011), as well as environmental noise; the velocity threshold is set at a level that is not expected to interfere with the classification of eye fixations and is appropriate given the varying levels of noise (Olsen 2012; Olsen and Matos 2012). Above the threshold, an eye movement is classified as a saccade, indicating the end of a fixation (Salvucci and Goldberg 2000).
} 
We then assess participants' skeptical action by asking them to select the sample size of accounts receivable items they would like to test (Nelson 2009; Brasel et al. 2019). The initial sample size recommended to participants was ten items based on the sample chosen in the prior year. However, after reviewing the client data file, participants were given the opportunity to choose any sample size between 0 to 30 items (i.e., ranging from testing 0 to 100 percent of the items in the accounts receivable listing). The measure of skeptical action is the difference between the prior year sample size and the participant's chosen sample size in the current year after reviewing the data file.

\section{Results of Experiment 1}

\section{Data reliability and attention checks}

Eye-tracking studies with questions and keystroke advancement can lead to data loss (Tobii AB 2016). Therefore, consideration of participant data quality, eye-tracking confidence, unusual gaze plot patterns (e.g., very long breaks between data samples), and failure to follow instructions led to the exclusion of five participants from the study (see Holmqvist et al. 2011 and Lynch and Andiola 2018 for recommendations on assessing eye tracking data quality). In addition, we included an attention check question as part of the post-experimental survey that asked participants to specifically select "1" on a scale to ensure participants were reading the questions. Four participants selected a number other than "1", suggesting they were not attending to the questions. These participants were removed from the study. Our final sample for Experiment 1 is 37 undergraduate and graduate students.

We included an attention check question to ascertain whether participants attended to the presence of errors using a 7-point scale from 1 (Strongly disagree) to 7 (Strongly agree). The question asked participants "Agree or Disagree - The file sent by the client appeared to contain potential errors". We find significant differences between conditions, with participants in the errors 
present condition more strongly agreeing that errors were present than those in the errors absent condition ( $p<0.05$, two-tailed). We also examined whether participants in the high information load treatment condition indicated a higher presence of errors than those in the low information load condition. There was no significant difference $(p>0.10)$ between the information load treatment conditions, providing evidence that information load did not influence participants' perceptions of the presence of errors. ${ }^{13}$

\section{Eye-tracking descriptives}

Before discussing the results of the hypothesis tests, we briefly summarize some of the insightful descriptives from our eye-tracking data. While our focus in this study is on the number of fixations in the overall client data file stimuli, we captured statistics on four distinct areas of interest (AOIs). These include the customer information column (far left), the invoice amount column (far right), the totals area (bottom right corner), and the overall spreadsheet (all of the visible area of the data file). In addition, in the two versions where minor errors were present, the four errors were identified as AOIs (two in the customer column, one in the date column, and one in the invoice total column) and aggregated in the descriptives provided in Table 1. Appendix B provides an illustration of how the AOIs were identified in the minor errors present/high information load condition.

\section{[INSERT TABLE 1]}

Table 1 provides means and standard deviations for three key eye-tracking measures: time to first fixation (i.e., how quickly the defined AOI captures the respondent's attention), number of fixations (i.e., our dependent variable of interest), and total visit duration (i.e., the amount of time that a participant spent gazing within the defined AOI). For all four treatments, the participants'

\footnotetext{
${ }^{13}$ Information load is a subliminal manipulation. As such, we do not include an attention check question for this variable in either experiment.
} 
eyes were attracted to the customer information first. This is expected given this column is the furthest to the left and English reading style is left to right (Orquin and Loose 2013). Participants in the high information load condition took significantly less time to focus on the customer column in the errors present condition than in the errors absent condition $(t=2.18, p<0.05)$. This may be because two of the minor errors appear in the customer column. In the low information load treatment, the errors present condition averaged a greater number of fixations and total duration than the errors absent condition, but none of the differences were significant. Importantly, in the high information load condition, there was a significantly greater number of fixations and a longer total duration for the customer column, invoice amounts column, and totals area, as well as the overall data file for the errors present condition than for the errors absent condition (all $p$-values < 0.05). This result is consistent with our predictions. Specifically, the combination of errors and higher information load seems to decrease individuals' abilities to interpret the information, making them focus more on the rest of the information in the data file.

\section{Hypothesis tests}

Table 2, panel A and panel B present descriptive statistics and a graphical representation of the effects of the presence of minor errors and information load on processing fluency. Hypothesis 1a predicts that the presence of minor errors decreases processing fluency more (i.e., a greater number of fixations) than when minor errors are absent (regardless of the level of information load). Results of a standard ANOVA, presented in Table 2, panel C, show a significant difference in number of fixations when errors are present versus absent $(\mathrm{F}=12.86, p=0.001$, twotailed), supporting Hypothesis 1a. However, these results need to be interpreted in light of a significant two-way interaction.

[INSERT TABLE 2] 
Hypothesis 2a predicts that the extent to which an auditor's processing fluency decreases when errors are present is greater when information load is higher versus when it is lower. The ANOVA results indicate a significant interaction between minor errors and information load $(\mathrm{F}=$ $5.61, p=0.024$, two-tailed). However, the ANOVA does not test for the specific predicted pattern illustrated in Figure 2. Therefore, we test our predicted pattern by deriving contrast weights outlined in Buckless and Ravenscroft (1990) and guided by Guggenmos et al. (2018). Our contrast weights are as follows: -2 in the minor errors absent/low information load condition, -2 in the minor errors absent/high information load condition, +1 in the minor errors present/low information load condition, and +3 in the minor errors present/high information load condition. This pattern of weights incorporates a greater difference between when errors are present and absent at high load, and a smaller difference at low load, consistent with our predictions in Hypothesis 2a. Results of this planned contrast are presented in Table 2, panel D. As expected, we find support for our predicted interaction ( $\mathrm{F}=19.06, p<0.001$, one-tailed). Using a semi-omnibus F-test, we identify that residual between-cells variance is insignificant $(\mathrm{F}=1.73, p=0.193)$ and calculate the proportion of cell variance not explained by the contrast $\left(q^{2}\right)$ as 16.4 percent. Collectively, these results support Hypothesis 2a.

To emphasize the importance that the combination of minor errors and high information load significantly decreases processing fluency, we also report simple effects tests in Table 2, panel E. These tests indicate that when minor errors are present, information load has a significant effect on processing fluency $(t=-2.251, p=0.016$, one-tailed), but when absent there is no difference ( $p$ $>0.10$ ). Alternatively, when information load is low, the presence of errors does not affect processing fluency $(p>0.10)$, but when information load is high the presence of errors is impactful $(t=-4.573, p<0.001$, one-tailed). These simple effects indicate that information load is not 
impactful when there is no "trigger" event (i.e., errors are absent), but load is influential on individuals' ability to process information when errors are present.

\section{Investigating the intermediary role of processing fluency on skeptical judgments and actions}

Nolder and Kadous (2018) highlight the importance of understanding the cognitive processes underlying an individual's skeptical judgments and actions, but they indicate that research on professional skepticism often omits examination of such processes. Prior research on processing fluency suggests that the ease with which information can be processed and interpreted influences an individual's subsequent judgments and decisions (Reber and Schwarz 1999; Lee and Labroo 2004; Rennekamp 2012). Therefore, we expect and test whether processing fluency explains the relationship between characteristics of client data files (i.e., minor errors and information load) and skeptical judgments, and, in turn, whether skeptical judgments influence skeptical actions (Nelson 2009; Hurtt et al 2013). Therefore, we conduct a path analysis using maximum likelihood estimation structural equation modeling in Stata Version 14 to investigate whether information load moderates the effect of minor errors on processing fluency, and whether this fluency has a direct positive association with an individual's skeptical judgment and action. ${ }^{14}$

Figure 3 presents the results of our path analysis. Overall, the hypothesized path model provides a good fit to the data $(\chi=6.47, p=0.486 ; \mathrm{CFI}=1.00 ; \mathrm{TLI}=1.04 ; \mathrm{RMSEA}=0.00 ; \mathrm{SRMR}$ $=0.08) .{ }^{15}$ Consistent with our primary results, the path analysis suggests that information load moderates the effect of minor errors on number of fixations (standardized regression weight $(\mathrm{SRW})=0.59, p<0.01$, one-tailed). Further, the number of fixations results in a greater change in

\footnotetext{
${ }^{14}$ Because Experiment 1 involves a small sample, we also estimated our model with 5,000 bootstrap replications. We find our results are identical except the significance of the association between the number of fixations and change in misstatement likelihood is slightly less ( $p<0.10$ vs. $p<0.05$ ).

${ }^{15}$ Five indices are used to assess the goodness of fit of the model: the $\chi^{2}$ test, the comparative fit index (CFI), the Tucker-Lewis index (TLI), the root mean square error of approximation (RMSEA) and the standardized root mean squared residual (SRMR). Prior literature suggests a good fit is obtained when the $\chi^{2}$ is not significant, the CFI and TLI are above the suggested 0.95 threshold, the RMSEA is below the suggested 0.06 threshold, and the SRMR is below the suggested 0.08 threshold (see Kline (2010) and Hampton (2015) for further guidance and associated suggested thresholds).
} 
misstatement likelihood (SRW $=0.25, p<0.05$, one-tailed), which increases the change in sample size (SRW $=0.37, p<0.05$, one-tailed). Collectively, these results provide evidence that characteristics of client data files (i.e., minor errors and information load) influence an individual's ability to interpret the information, which, in turn, affects both skeptical judgments and actions.

\section{[INSERT FIGURE 3]}

\section{Experiment 2 method and results}

Experiment 2 uses 97 accounting professionals with an average of 9.5 years of public accounting experience to investigate the effects of minor errors and information load on auditors' skeptical judgments and actions, testing Hypotheses $1 \mathrm{~b}$ and $2 \mathrm{~b}$. The experimental design, task and procedures, and variables in Experiment 2 closely mirror those of Experiment 1. Below we discuss the differentiating factors.

\section{Experimental design}

Experiment 2 also uses a $2 \times 2$ design in which we manipulate between subjects the presence of minor errors (absent versus present) and information load (low versus high) in a clientprepared data file. Participants' skeptical judgments and skeptical actions were measured in the same manner as Experiment 1. The experimental materials were delivered to participants online via Qualtrics instrument delivery software. The materials included an information sheet describing the experiment and the voluntary nature of participating, four screening questions, the case scenario described in Experiment 1 above, and a post-experimental survey. ${ }^{16}$

\footnotetext{
${ }^{16}$ The only differentiating feature in the task for Experiment 2 was that, because of the online nature of the experiment and the cost of participants, the instrument required that participants stay on the client data file screen for at least 20 seconds. The average time participants viewed this screen across all four treatments was 60 seconds.
} 


\section{Participants}

Participants were recruited and paid via Qualtrics Panel, a participant recruitment service used in several other recent accounting studies (e.g., Nelson and Rupar 2015; Long and Basoglu 2016). ${ }^{17}$ Participants included in our study had to pass a four question screening test to assess whether they had an appropriate level of accounting experience and auditing knowledge to complete the task. Participants who answered any question incorrectly were not allowed to participate in the study. ${ }^{18}$ Of those that passed the initial screening test, 71 percent are Certified Public Accountants, 52 percent have experience working at a global firm (e.g., KPMG, PWC, Grant Thornton), and 44 percent are male. We assessed their trait-level professional skepticism using the Hurtt scale (Hurtt 2010). Our professional participants' trait-level skepticism on average is 75.6 (100-point scale), similar to other studies using professional accountants (e.g., mean $=75.5$ in Peytcheva (2014); mean $=73.9$ in Quadackers et al. (2014)). Participants were randomly assigned to one of the four treatment conditions. ${ }^{19}$

As part of our post-experimental survey, we asked participants for their perspectives on the extent and effects of client-prepared data files that are messy and/or dirty (e.g., records that include minor errors, irrelevant information, and/or disorganized information). We asked all participants how frequently they encounter messy/dirty audit files from clients using a 7-point scale from 1 (Never) to 7 (All the time). Participants reported that on average they encounter messy/dirty files between occasionally and frequently (mean $=4.2 ; \mathrm{SD}=1.3$ ). We also asked whether messy/dirty client files impact their application of professional skepticism using a 7-point scale from 1 (Strongly disagree) to 7 (Strongly agree). Participants somewhat agree to agree that these files

\footnotetext{
${ }^{17}$ See Brandon et al. (2014) for an in-depth discussion of Qualtrics Panels and Qualtrics's online instrument delivery software. ${ }^{18}$ Qualtrics does not disclose the number of participants who do not pass the initial screening questions or the amount they pay participants. While participation is voluntary, Qualtrics only compensates participants if they complete the full instrument. We paid Qualtrics 40 dollars for each qualified participant. We did not have any direct contact with our participants.

${ }^{19}$ Participant trait-level skepticism was not significantly different between conditions and not significant in our hypothesis tests.
} 
impact their application of skepticism (mean $=5.4 ; \mathrm{SD}=1.2)$. Finally, we asked participants what percent of their time is spent cleaning up messy/dirty client files. Our participants reported that on average 32 percent of their time $(\mathrm{SD}=18.4)$ is spent cleaning up messy/dirty client files. These perspectives from professionals in practice indicate that dirty client data files are common, affect the application of professional skepticism, and require significant time to clean up.

\section{Results of Experiment 2}

\section{Attention checks}

The same attention check question in Experiment 1 was also used for the professional participants in Experiment 2. We find significant differences between conditions, with participants in the error present condition more strongly agreeing that errors were present compared to those in the errors absent condition $(p<0.01$, two-tailed $) .{ }^{20}$ We also examined whether participants in the high information load treatment condition indicated a higher presence of errors than those in the low information load condition. There was no significant difference $(p>0.10)$ between the information load treatment conditions, providing evidence that information load did not influence participants' perceptions of the presence of errors.

\section{Hypothesis tests}

Table 3, panel A and panel B (Table 4, panel A and panel B) presents descriptive statistics and a graphical representation of the presence of minor errors and information load on change in misstatement likelihood (change in sample size). Hypothesis $1 \mathrm{~b}$ predicts that the presence of minor errors will lead to greater skeptical judgment and skeptical action than when minor errors are absent. Results of a standard ANOVA for change in misstatement likelihood, presented in Table 3, panel $\mathrm{C}$, show a significant difference when errors are present versus absent $(\mathrm{F}=5.33 ; p=0.023$,

\footnotetext{
${ }^{20} \mathrm{We}$ also find that participants assess their confidence in the client's competence significantly lower when errors are present versus when they are absent $(t=6.121, p<0.001$, two-tailed), consistent with prior research (e.g., Luippold et al. 2015). Perceptions of client's competence were not influenced by information load $(t=-0.905, p>0.10)$.
} 
two-tailed). ANOVA results for change in sample size, presented in Table 4, panel C, also show a significant difference when errors are present versus absent $(\mathrm{F}=4.97, p=0.028$, two-tailed $){ }^{21}$ These results provide support for Hypothesis $1 \mathrm{~b}$.

[INSERT TABLE 3 AND TABLE 4]

Hypothesis $2 \mathrm{~b}$ predicts that the extent to which an auditor's skeptical judgments and skeptical actions will increase when errors are present is greater when information load is higher versus when it is lower. The ANOVA results in Table 3, panel $\mathrm{C}$ and Table 4, panel $\mathrm{C}$ do not indicate a significant interaction between minor errors and information load on either changes in misstatement likelihood or changes in sample size. However, similar to Hypothesis 2 a we expected a specific pattern of results that is not tested by an ANOVA. Therefore, we tested our predicted pattern using the same contrasts weights indicated in our Experiment 1 results above. This pattern of weights incorporates a greater difference between when errors are present and absent at high load, and a smaller difference at low load, consistent with our predictions in Hypothesis $2 \mathrm{~b}$. Results of the planned contrasts are presented in Table 3, panel D and Table 4, panel D. As expected, we find support for our expected pattern of results for both change in misstatement likelihood $(\mathrm{F}=$ $6.20, p=0.008$, one-tailed $)$ and change in sample size $(\mathrm{F}=7.30, p=0.004$, one-tailed $)$. Using a semi-omnibus F-test, we also identify that residual between-cells variance is insignificant for both judgments $(\mathrm{F}=0.42, p=0.661)$ and actions $(\mathrm{F}=1.08, p=0.343)$ and calculate the proportion of cell variance not explained by the contrast $\left(q^{2}\right)$ as 11.0 and 21.5 percent, respectively. Collectively, these results support Hypothesis $2 \mathrm{~b}$.

We also report simple effects tests in Table 3, panel E and Table 4, panel E. First, the results in Table 3, panel E indicate that there is no difference in the effects of information load on skeptical

\footnotetext{
${ }^{21}$ Table 4, panel $\mathrm{C}$ also shows an unpredicted main effect of information load $(\mathrm{F}=4.94, p=0.029$, two-tailed).
} 
judgment when minor errors are present or absent $(p>0.10$ in both). However, when information load is low or high, the effects of the presence of errors is significant on skeptical judgment $(t=-$ $1.57, p=0.06$, one tailed and $t=-1.71, p=0.046$, one-tailed, respectively). These simple effects indicate that information load may not be directly impactful on skeptical judgment, but the presence of minor errors is. Turning to Table 4, panel E, results suggest that when minor errors are present, information load has a significant effect on skeptical action $(t=2.06, p=0.021$, onetailed), but when absent there is no difference $(p>0.10)$. Alternatively, when information load is low, the presence of errors does not affect skeptical judgment $(p>0.10)$, but when information load is high the presence of errors is impactful ( $t=-1.98, p=0.025$, one-tailed). Collectively, these results suggest that the combination of the presence of errors and high information load significantly increases skeptical actions. Interestingly, results of Experiment 2 suggest the presence of errors alone do not increase auditor's skeptical actions, even though their skeptical judgment increased indicating a disconnect between auditors' judgments and actions.

\section{Conclusion}

Applying an appropriate level of skepticism continues to be an important issue for both audit firms and regulators (e.g., PCAOB 2012; KPMG 2017). While regulators frequently criticize auditors for not being skeptical enough (e.g., Franzel 2013; IFIAR 2018), taking too much of a "presumptive doubt" approach to skepticism (i.e., Quadackers et al. 2014) can result in excessive evidence gathering in one area that could limit the time and/or resources an auditor has available to devote to other areas. A scenario that may produce a suboptimal balance of effectiveness and efficiency (Nelson 2009; Glover and Prawitt 2014). Client-prepared data files are a key source of information that may affect an auditor's level of skepticism when conducting audit work. In this study, we examine whether two common features of client-prepared data files, the presence (or 
absence) of minor errors and information load (low or high), influence the ease with which client information can be interpreted, as well as the effects on auditors' skeptical judgments and actions.

Overall, our results indicate that features of client-prepared data files can significantly influence auditors' abilities to process and evaluate information, resulting in skeptical judgments and actions that are sometimes excessive. Importantly, our professional participants indicate that they frequently encounter "dirty" data files in audit practice and believe that these files are likely to influence their level of professional skepticism. Our results also show that when minor errors are present versus absent, individuals' processing fluency decreases and skeptical judgments and actions increase. Next, our results indicate the combination of the presence of minor errors and higher information load decreases processing fluency and increases skeptical actions more than when minor errors are absent or when information load is lower. However, we did not find this result for skeptical judgments. Importantly, using a path analysis, we find that as participants' abilities to interpret the client-provided information decreases, their skeptical judgments increase, and, in turn, their skeptical actions increase.

From a practical perspective, our results are important because while minor errors should make an auditor question the accuracy of information provided in client data files, information load should not. However, if the combination of errors and load lead to reductions in processing fluency, and, in turn, to excessive skepticism, then auditors may spend too much time on the wrong audit areas. This result is likely to put increased time and budget pressure on auditors that may encourage them to reduce work in other areas or engage in reduced audit quality acts (e.g., Coram et al. 2004). Griffith et al. (2016) encourage researchers to investigate whether it is possible to trigger chronic availability of goals to induce skeptical behavior, but chronic availability could 
have an unintended effect. Specifically, while not having enough skepticism is clearly problematic, having too much skepticism in the wrong areas may also reduce audit quality.

Our study makes several important contributions to the auditing literature. First, we study two highly prevalent characteristics of client-prepared data files (an environmental factor) that the audit literature has not previously examined (see Bonner 2008). Second, we advance the literature that investigates professional skepticism by studying one of the underlying cognitive processes, processing fluency, that lead to differences in skeptical judgments and actions (Nolder and Kadous 2018). In addition, by examining the influence of information load on auditors' judgments and decisions we provide some initial evidence of the possible consequences of auditors having to analyze Big Data (Brown-Liburd et al. 2015). Finally, our study contributes to the evolving literature on eye tracking in a professional context and is the first audit study to use an eye tracker to measure underlying cognitive processes affecting auditors' judgments (Orquin and Loose 2013; Lynch and Andiola 2018; Meißner and Oll 2019).

Our findings point to potentially fruitful areas for future research. First, we only examine two characteristics of client-prepared data files; future research could consider others (e.g., variations in format, level of organization). We also specifically focus on the planning phase of the audit and emphasize effects on skeptical judgments and actions. However, whether features of client-prepared data files may be impactful in other phases (e.g., internal control and substantive testing) and affect other outcomes (e.g., effort, task performance) may also be valuable and insightful. In addition, we focus on using the "dirty" file as is, but auditors may have other options when they receive dirty client-provided data files, including sending the file back to the client to clean them up or cleaning up the files themselves. Future research may consider how the client fixing the file or the auditor fixing the file before judgments and decisions are made could change 
auditors' responses. In addition, given the extent that dirty client-prepared data files are provided to auditors and the significant time auditors incur to clean them up, future research may investigate how auditors' challenges with client data files may be overcome. Perhaps training on appropriate ways to evaluate and clean client data files could help and/or make auditors aware of the natural biases that may occur when evaluating client-provided data files or the use of artificial intelligence to clean and scrub files before an auditor actually evaluates them may be a viable option.

Although our task is fairly simple, it reflects an important and commonly occurring task that auditors encounter. As is true in many experimental studies, we examine a setting that sacrifices external validity in exchange for internal validity. However, the control obtained in our setting permits us to test theory that should generalize to other settings. Future studies may wish to extend this research by examining elements that arise in settings that are more complex that may moderate or mediate the effects documented in this study. With the advent of Big Data, we expect that the amount of data that clients provide is likely to increase exponentially, potentially exacerbating the strains on processing fluency documented in this study. 


\section{Appendix A \\ Illustrations of client-provided data file in the four treatment conditions}

Treatment 1: Minor errors absent, low information load

\begin{tabular}{|c|c|c|c|c|c|c|}
\hline \multicolumn{2}{|c|}{$\triangle \mathrm{A}$} & B & C & \multirow[t]{2}{*}{ D } & \multicolumn{2}{|r|}{$\mathrm{F}$} \\
\hline 1 & \multicolumn{3}{|c|}{ A/R Balance as of: 12/31/2015 } & & PBC & \\
\hline \multicolumn{7}{|l|}{2} \\
\hline 3 & & Customer & Invoice Number & Invoice Date & Invoice Amount & \\
\hline 4 & 1 & Sinus Aide & 41569 & $9 / 27 / 2015$ & $45,767.90$ & \\
\hline 5 & 2 & Jay \& Jack's Auto Oil & 41624 & $10 / 9 / 2015$ & $247,694.30$ & \\
\hline 6 & 3 & Generic Cola Inc. & 41687 & $10 / 18 / 2015$ & $6,264.85$ & \\
\hline 7 & 4 & Florida Juice Corp & 41699 & $11 / 3 / 2015$ & $68,585.40$ & \\
\hline 8 & 5 & Mars Liquid Detergents & 41700 & $11 / 6 / 2015$ & $385,948.00$ & \\
\hline 9 & 6 & Silver Springs & 41711 & $11 / 9 / 2015$ & $45,825.31$ & \\
\hline 10 & 7 & Penns Oil & 41756 & $11 / 14 / 2015$ & $112,375.20$ & \\
\hline 11 & 8 & Jay \& Jack's Auto Oil & 41764 & $11 / 17 / 2015$ & $1,482,229.00$ & \\
\hline 12 & 9 & Petrol TX & 41767 & $11 / 20 / 2015$ & $1,765,900.99$ & \\
\hline 13 & 10 & Penns Oil & 41768 & $11 / 23 / 2015$ & $57,459.00$ & \\
\hline 14 & 11 & The Bath \& Body Shop & 41786 & $11 / 28 / 2015$ & $412,426.15$ & \\
\hline 15 & 12 & Fresh Squeezed & 41788 & $12 / 1 / 2015$ & $25,478.96$ & \\
\hline 16 & 13 & Olivier's Olive Oil & 41811 & $12 / 4 / 2015$ & $12,339.37$ & \\
\hline 17 & 14 & Petrol TX & 41845 & $12 / 5 / 2015$ & $3,765,490.00$ & \\
\hline 18 & 15 & Petrol TX & 41877 & $12 / 8 / 2015$ & $2,780,008.12$ & \\
\hline 19 & 16 & Windox & 41887 & $12 / 6 / 2015$ & $311,411.42$ & \\
\hline 20 & 17 & Soup to Go & 41888 & $12 / 11 / 2015$ & $56,287.11$ & \\
\hline 21 & 18 & Liquid Chocolate & 41889 & $12 / 14 / 2015$ & $89,541.50$ & \\
\hline 22 & 19 & Drinks R Us & 41895 & $12 / 15 / 2015$ & $98,546.25$ & \\
\hline 23 & 20 & Alligator Aid & 41900 & $12 / 18 / 2015$ & 261.71 & \\
\hline 24 & 21 & Pure Oil & 41903 & $12 / 20 / 2015$ & $298,475.00$ & \\
\hline 25 & 22 & Diet Water & 41965 & $12 / 27 / 2015$ & $287,483.13$ & \\
\hline 26 & 23 & Anna's Aromatherapy & 41990 & $12 / 28 / 2015$ & $933,652.00$ & \\
\hline 27 & 24 & Kiddel Co. & 42001 & $12 / 28 / 2015$ & $8,152,858.95$ & \\
\hline 28 & 25 & Vat O Wine & 42002 & $12 / 29 / 2015$ & $88,666.00$ & \\
\hline 29 & 26 & Kiddel Co. & 42010 & $12 / 29 / 2015$ & $6,745,714.15$ & \\
\hline 30 & 27 & Mountain Water & 42012 & $12 / 29 / 2015$ & $6,144,758.61$ & \\
\hline 31 & 28 & Kiddel Co. & 42013 & $12 / 29 / 2015$ & $10,389,546.16$ & \\
\hline 32 & 29 & Mountain Water & 42070 & $12 / 29 / 2015$ & $3,456,784.42$ & \\
\hline 33 & 30 & Kiddel Co. & 42075 & $12 / 30 / 2015$ & $2,456,382.00$ & \\
\hline 34 & & & & & & \\
\hline 35 & & & & Sum Total: & $50,724,160.96$ & $6 \mathrm{GL}$ \\
\hline 36 & & & & Total per GL: & $50,724,160.96$ & \\
\hline 37 & & & & & & \\
\hline
\end{tabular}

Treatment 2: Minor errors absent, high information load

\begin{tabular}{|c|c|c|c|c|c|c|c|c|c|c|c|c|}
\hline \multicolumn{2}{|c|}{$\triangle \mathrm{A}$} & B & $\mathrm{C}$ & \multirow[t]{2}{*}{ D } & \multirow[t]{2}{*}{$E$} & \multirow[t]{2}{*}{$\mathrm{F}$} & \multirow[t]{2}{*}{ G } & \multirow[t]{2}{*}{$\mathrm{H}$} & \multirow[t]{2}{*}{ I } & \multirow[t]{2}{*}{$\mathrm{J}$} & $\mathrm{K}$ & \multirow{2}{*}{$c^{L}$} \\
\hline \multirow{2}{*}{$\begin{array}{l}1 \\
2\end{array}$} & \multicolumn{3}{|c|}{ A/R Balance as of: 12/31/2015 } & & & & & & & & PBC & \\
\hline & & & & & & & & & & & & \\
\hline 3 & & Customer & State & \begin{tabular}{|l|} 
Invoice \\
Number
\end{tabular} & Phone & Contact & $\begin{array}{c}\text { Invoice } \\
\text { Date }\end{array}$ & Items & Number & Skew & $\begin{array}{l}\text { Invoice } \\
\text { Amount }\end{array}$ & \\
\hline 4 & 1 & Sinus Aide & VA & 41569 & $x x x-x x x x$ & J. Johnson & $9 / 27 / 2015$ & A bottles & 1,000 & $\mathrm{AF}$ & $45,767.90$ & \\
\hline 5 & 2 & Jay \& Jack's Auto Oil & $\mathrm{DE}$ & 41624 & $x x x-x x x x$ & Pete Barnell & $10 / 9 / 2015$ & AA bottles & 5,000 & AF1 & $247,694.30$ & \\
\hline 6 & 3 & Generic Cola Inc. & NY & 41687 & $x x x-x x x x$ & Ben Anderson & $10 / 18 / 2015$ & $\mathrm{C}$ bottles & 500 & $\mathrm{~F}$ & $6,264.85$ & \\
\hline 7 & 4 & Florida Juice Corp & $\mathrm{FL}$ & 41699 & $x x x-x x x x$ & Guy M. & $11 / 3 / 2015$ & $\mathrm{~F}$ bottles & 800 & B & $68,585.40$ & \\
\hline 8 & 5 & Mars Liquid Detergents & VA & 41700 & $x x x-x x x x$ & Bob Lynch & $11 / 6 / 2015$ & A bottles & 6,000 & AF & $385,948.00$ & \\
\hline 9 & 6 & Silver Springs & MD & 41711 & $x x x-x x x x$ & Sharon S. & $11 / 9 / 2015$ & A bottles & 4,500 & AF & $45,825.31$ & \\
\hline 10 & 7 & Penns Oil & TX & 41756 & $x x x-x x x x$ & Chandler Moore & $11 / 14 / 2015$ & $\mathrm{C}$ bottles & 6,100 & $\mathrm{~F}$ & $112,375.20$ & \\
\hline 11 & 8 & Jay \& Jack's Auto Oil & WA & 41764 & $x x x-x x x x$ & Sam Sparx & $11 / 17 / 2015$ & B bottles & 10,000 & $\mathrm{C} 2$ & $1,482,229.00$ & \\
\hline 12 & 9 & Petrol TX & TX & 41767 & $x x x-x x x x$ & Tom S. & $11 / 20 / 2015$ & $Z$ bottles & 10,000 & FB12 & $1,765,900.99$ & \\
\hline 13 & 10 & Penns Oil & TX & 41768 & $x x x-x x x x$ & Chandler Moore & $11 / 23 / 2015$ & T bottles & 3,000 & $X X 2$ & $57,459.00$ & \\
\hline 14 & 11 & The Bath \& Body Shop & WA & 41786 & $x x x-x x x x$ & Jess Wyman & $11 / 28 / 2015$ & B bottles & 25,000 & $\mathrm{C} 2$ & $412,426.15$ & \\
\hline 15 & 12 & Fresh Squeezed & $\mathrm{FL}$ & 41788 & $x x x-x x x x$ & Andy Goodman & $12 / 1 / 2015$ & T bottles & 2,000 & $x \times 2$ & $25,478.96$ & \\
\hline 16 & 13 & Olivier's Olive Oil & $\mathrm{CA}$ & 41811 & $x x x-x x x x$ & Rachel Horn & $12 / 4 / 2015$ & $\mathrm{~F}$ bottles & 1,500 & B & $12,339.37$ & \\
\hline 17 & 14 & Petrol TX & TX & 41845 & $x x x-x x x x$ & Tom S. & $12 / 5 / 2015$ & $Z$ bottles & 30,000 & FB12 & $3,765,490.00$ & \\
\hline 18 & 15 & Petrol TX & TX & 41877 & $x x x-x x x x$ & Tom S. & $12 / 8 / 2015$ & $Z$ bottles & 25,000 & FB12 & $2,780,008.12$ & \\
\hline 19 & 16 & Windox & TN & 41887 & $x x x-x x x x$ & Robert Hitchcock & $12 / 6 / 2015$ & AA bottles & 6,000 & AF1 & $311,411.42$ & \\
\hline 20 & 17 & Soup to Go & SC & 41888 & $x x x-x x x x$ & Cameron Baxter & $12 / 11 / 2015$ & A bottles & 2,000 & AF & $56,287.11$ & \\
\hline 21 & 18 & Liquid Chocolate & $\mathrm{CA}$ & 41889 & $x x x-x x x x$ & Toby Guan & $12 / 14 / 2015$ & $\mathrm{~F}$ bottles & 8,000 & B & $89,541.50$ & \\
\hline 22 & 19 & Drinks R Us & $\mathrm{CA}$ & 41895 & $x x x-x x x x$ & Daniel Brown & $12 / 15 / 2015$ & B bottles & 6,000 & $\mathrm{~F}$ & $98,546.25$ & \\
\hline 23 & 20 & Alligator Aid & $\mathrm{FL}$ & 41900 & $x x x-x x x x$ & Aisha Phung & $12 / 18 / 2015$ & $Z$ bottles & 25 & FB12 & 261.71 & \\
\hline 24 & 21 & Pure Oil & $\mathrm{CA}$ & 41903 & $x x x-x x x x$ & Sarah Creighton & $12 / 20 / 2015$ & $\mathrm{C}$ bottles & 3,000 & $\mathrm{~F}$ & $298,475.00$ & \\
\hline 25 & 22 & Diet Water & $\mathrm{CA}$ & 41965 & $x x x-x x x x$ & Johnathon Head & $12 / 27 / 2015$ & B bottles & 3,100 & $\mathrm{C} 2$ & $287,483.13$ & \\
\hline 26 & 23 & Anna's Aromatherapy & WA & 41990 & $x x x-x x x x$ & Jerry & $12 / 28 / 2015$ & AA bottles & 4,500 & AF & $933,652.00$ & \\
\hline 27 & 24 & Kiddel Co. & $\mathrm{GA}$ & 42001 & $x x x-x x x x$ & Eddie Jones & $12 / 28 / 2015$ & AA bottles & 50,000 & AF & $8,152,858.95$ & \\
\hline 28 & 25 & Vat O Wine & WA & 42002 & $x x x-x x x x$ & Dale C. & $12 / 29 / 2015$ & $\mathrm{~F}$ bottles & 7,000 & B & $88,666.00$ & \\
\hline 29 & 26 & Kiddel Co. & GA & 42010 & $x x x-x x x x$ & Eddie Jones & $12 / 29 / 2015$ & AA bottles & 50,000 & AF1 & $6,745,714.15$ & \\
\hline 30 & 27 & Mountain Water & $\mathrm{CO}$ & 42012 & $x x x-x x x x$ & William Stewart & $12 / 29 / 2015$ & $\mathrm{C}$ bottles & 50,000 & $\mathrm{C} 2$ & $6,144,758.61$ & \\
\hline 31 & 28 & Kiddel $\mathrm{Co}$. & GA & 42013 & $x x x-x x x x$ & Eddie Jones & $12 / 29 / 2015$ & T bottles & 60,000 & $\mathrm{C} 2$ & $10,389,546.16$ & \\
\hline 32 & 29 & Mountain Water & $\mathrm{CO}$ & 42070 & $x x x-x x x x$ & William Stewart & $12 / 29 / 2015$ & $\mathrm{C}$ bottles & 30,000 & $\mathrm{C} 2$ & $3,456,784.42$ & \\
\hline 33 & 30 & Kiddel Co. & GA & 42075 & $x x x-x x x x$ & Eddie Jones & $12 / 30 / 2015$ & $\mathrm{C}$ bottles & 20,000 & $\mathrm{C} 2$ & $2,456,382.00$ & \\
\hline 34 & & & & & & & & & & & & \\
\hline 35 & & & & & & & & & & Total: & $50,724,160.96$ & GL \\
\hline 36 & & & & & & & & & Total & er GL: & $50,724,160.96$ & \\
\hline
\end{tabular}


Treatment 3: Minor errors present, low information load

\begin{tabular}{|c|c|c|c|c|c|c|}
\hline 4 & A & B & C & D & $E$ & $\mathrm{~F}$ \\
\hline 1 & AR & Balance as of: $12 / 31 / 201$ & & & PBC & \\
\hline 2 & & & & & & \\
\hline 3 & & Customer & Invoice Number & Invoice Date & Invoice Amount & \\
\hline 4 & 1 & Sinus Aide & 41569 & $9 / 27 / 2015$ & $45,767.90$ & \\
\hline 5 & 2 & Jay \& Jack's Auto Oil & 41624 & 10/9/2015 & $247,694.30$ & \\
\hline 6 & 3 & Generic Cola Inc. & 41687 & $10 / 18 / 2015$ & $6,264.85$ & \\
\hline 7 & 4 & Florida Juice Corp & 41699 & $11 / 3 / 2015$ & $68,585.40$ & \\
\hline 8 & 5 & Mars Liquid Detergents & 41700 & $11 / 6 / 2015$ & $385,948.00$ & \\
\hline 9 & 6 & Silver Springs & 41711 & $11 / 9 / 2015$ & $45,825.31$ & \\
\hline 10 & 7 & Penns Oil & 41756 & $11 / 14 / 2015$ & $112,375.20$ & \\
\hline 11 & 8 & Jay \& Jack's Auto Oil & 41764 & $11 / 17 / 2015$ & $1,482,229.00$ & \\
\hline 12 & 9 & Petrol TX & 41767 & $11 / 20 / 2015$ & $1,765,900.99$ & \\
\hline 13 & 10 & Penns Oil & 41768 & $11 / 23 / 2015$ & $57,459.00$ & \\
\hline 14 & 11 & The Bath \& Body Shop & 41786 & $11 / 28 / 2015$ & $412,426.15$ & \\
\hline 15 & 12 & Fresh Squeezed & 41788 & $12 / 1 / 2015$ & $25,478.96$ & \\
\hline 16 & 13 & Olivier's Olive Oil & 41811 & $12 / 4 / 2015$ & $12,339.37$ & \\
\hline 17 & 14 & Petrol TX & 41845 & $12 / 5 / 2015$ & $3,765,490.00$ & \\
\hline 18 & 15 & & 41877 & $12 / 8 / 2015$ & $2,780,008.12$ & \\
\hline 19 & 16 & Windox & 41887 & $12 / 6 / 2015$ & $311,411.42$ & \\
\hline 20 & 17 & Soup to Go & 41888 & $12 / 11 / 2015$ & $56,287.11$ & \\
\hline 21 & 18 & Liquid Chocolate & 41889 & $12 / 14 / 2015$ & $89,541.50$ & \\
\hline 22 & 19 & Drinks R Us & 41895 & 5782 & $98,546.25$ & \\
\hline 23 & 20 & Alligator Aid & 41900 & $12 / 18 / 2015$ & 261.71 & \\
\hline 24 & 21 & Pure Oil & 41903 & $12 / 20 / 2015$ & $298,475.00$ & \\
\hline 25 & 22 & Diet Water & 41965 & $12 / 27 / 2015$ & $287,483.13$ & \\
\hline 26 & 23 & Anna's Aromatherapy & 41990 & $12 / 28 / 2015$ & $933,652.00$ & \\
\hline 27 & 24 & Kiddel $\mathrm{Co}$. & 42001 & $12 / 28 / 2015$ & $8,152,858.95$ & \\
\hline 28 & 25 & Vat O Wine & 42002 & $12 / 29 / 2015$ & $A B C$ & \\
\hline 29 & 26 & Kiddel Co. & 42010 & $12 / 29 / 2015$ & $6,745,714.15$ & \\
\hline 30 & 27 & Mountain Water & 42012 & $12 / 29 / 2015$ & $6,144,758.61$ & \\
\hline 31 & 28 & & 42013 & $12 / 29 / 2015$ & $10,389,546.16$ & \\
\hline 32 & 29 & Mountain Water & 42070 & $12 / 29 / 2015$ & $3,456,784,42$ & \\
\hline 33 & 30 & Kiddel Co. & 42075 & $12 / 30 / 2015$ & $2,456,382.00$ & \\
\hline 34 & & & & & & \\
\hline 35 & & & & Sum Total: & $48,179,112.96$ & GL \\
\hline 36 & & & & Total per GL: & $50,724,160.96$ & \\
\hline 37 & & & & & & \\
\hline
\end{tabular}

Treatment 4: Minor errors present, high information load

\begin{tabular}{|c|c|c|c|c|c|c|c|c|c|c|c|c|}
\hline \multicolumn{2}{|c|}{$\triangle \mathrm{A}$} & $\mathrm{B}$ & $\mathrm{C}$ & \multirow[t]{2}{*}{ D } & \multirow[t]{2}{*}{$E$} & \multirow[t]{2}{*}{$\mathrm{F}$} & \multirow[t]{2}{*}{ G } & \multirow[t]{2}{*}{$\mathrm{H}$} & \multirow[t]{2}{*}{1} & \multirow[t]{2}{*}{$\mathrm{J}$} & K & \\
\hline \multirow{2}{*}{$\begin{array}{l}1 \\
2\end{array}$} & \multicolumn{3}{|c|}{ A/R Balance as of: $12 / 31 / 2015$} & & & & & & & & PBC & \\
\hline & & & & & & & & & & & & \\
\hline 3 & & Customer & State & \begin{tabular}{|l|} 
Invoice \\
Number
\end{tabular} & Phone & Contact & $\begin{array}{c}\text { Invoice } \\
\text { Date }\end{array}$ & Items & Number & Skew & $\begin{array}{l}\text { Invoice } \\
\text { Amount }\end{array}$ & \\
\hline 4 & 1 & Sinus Aide & VA & 41569 & $x x x-x x x x$ & J. Johnson & $9 / 27 / 2015$ & A bottles & 1,000 & $\mathrm{AF}$ & $45,767.90$ & \\
\hline 5 & 2 & Jay \& Jack's Auto Oil & $\mathrm{DE}$ & 41624 & $x x x-x x x x$ & Pete Barnell & $10 / 9 / 2015$ & AA bottles & 5,000 & AF1 & $247,694.30$ & \\
\hline 6 & 3 & Generic Cola Inc. & NY & 41687 & $x x x-x x x x$ & Ben Anderson & $10 / 18 / 2015$ & $\mathrm{C}$ bottles & 500 & $\mathrm{~F}$ & $6,264.85$ & \\
\hline 7 & 4 & Florida Juice Corp & $\mathrm{FL}$ & 41699 & $x x x-x x x x$ & Guy M. & $11 / 3 / 2015$ & F bottles & 800 & B & $68,585.40$ & \\
\hline 8 & 5 & Mars Liquid Detergents & VA & 41700 & $x x x-x x x x$ & Bob Lynch & $11 / 6 / 2015$ & A bottles & 6,000 & AF & $385,948.00$ & \\
\hline 9 & 6 & Silver Springs & MD & 41711 & $x x x-x x x x$ & Sharon S. & $11 / 9 / 2015$ & A bottles & 4,500 & AF & $45,825.31$ & \\
\hline 10 & 7 & Penns Oil & TX & 41756 & $x x x-x x x x$ & Chandler Moore & $11 / 14 / 2015$ & $\mathrm{C}$ bottles & 6,100 & $\mathrm{~F}$ & $112,375.20$ & \\
\hline 11 & 8 & Jay \& Jack's Auto Oil & WA & 41764 & $x x x-x x x x$ & Sam Sparx & $11 / 17 / 2015$ & $\mathrm{~B}$ bottles & 10,000 & C2 & $1,482,229.00$ & \\
\hline 12 & 9 & Petrol TX & TX & 41767 & $x x x-x x x x$ & Tom S. & $11 / 20 / 2015$ & $Z$ bottles & 10,000 & FB12 & $1,765,900.99$ & \\
\hline 13 & 10 & Penns Oil & TX & 41768 & $x x x-x x x x$ & Chandler Moore & $11 / 23 / 2015$ & T bottles & 3,000 & $\mathrm{XX2}$ & $57,459.00$ & \\
\hline 14 & 11 & The Bath \& Body Shop & WA & 41786 & $x x x-x x x x$ & Jess Wyman & $11 / 28 / 2015$ & B bottles & 25,000 & $\mathrm{C} 2$ & $412,426.15$ & \\
\hline 15 & 12 & Fresh Squeezed & $\mathrm{FL}$ & 41788 & $x x x-x x x x$ & Andy Goodman & $12 / 1 / 2015$ & $\mathrm{~T}$ bottles & 2,000 & $X X 2$ & $25,478.96$ & \\
\hline 16 & 13 & Olivier's Olive Oil & $\mathrm{CA}$ & 41811 & $x x x-x x x x$ & Rachel Horn & $12 / 4 / 2015$ & $\mathrm{~F}$ bottles & 1,500 & B & $12,339.37$ & \\
\hline 17 & 14 & Petrol TX & TX & 41845 & $x x x-x x x x$ & Tom S. & $12 / 5 / 2015$ & $Z$ bottles & 30,000 & FB12 & $3,765,490.00$ & \\
\hline 18 & 15 & & TX & 41877 & $x x x-x x x x$ & Tom S. & $12 / 8 / 2015$ & $Z$ bottles & 25,000 & FB12 & $2,780,008.12$ & \\
\hline 19 & 16 & Windox & TN & 41887 & $x x x-x x x x$ & Robert Hitchcock & $12 / 6 / 2015$ & AA bottles & 6,000 & AF1 & $311,411.42$ & \\
\hline 20 & 17 & Soup to Go & $\mathrm{SC}$ & 41888 & $x x x-x x x x$ & Cameron Baxter & $12 / 11 / 2015$ & A bottles & 2,000 & AF & $56,287.11$ & \\
\hline 21 & 18 & Liquid Chocolate & $\mathrm{CA}$ & 41889 & $x x x-x x x x$ & Toby Guan & $12 / 14 / 2015$ & $\mathrm{~F}$ bottles & 8,000 & B & $89,541.50$ & \\
\hline 22 & 19 & Drinks R Us & $\mathrm{CA}$ & 41895 & $x x x-x x x x$ & Daniel Brown & 5782 & $\mathrm{~B}$ bottles & 6,000 & $\mathrm{~F}$ & $98,546.25$ & \\
\hline 23 & 20 & Alligator Aid & $\mathrm{FL}$ & 41900 & $x x x-x x x x$ & Aisha Phung & $12 / 18 / 2015$ & $Z$ bottles & 25 & FB12 & 261.71 & \\
\hline 24 & 21 & Pure Oil & CA & 41903 & $x x x-x x x x$ & Sarah Creighton & $12 / 20 / 2015$ & $\mathrm{C}$ bottles & 3,000 & $\mathrm{~F}$ & $298,475.00$ & \\
\hline 25 & 22 & Diet Water & $\mathrm{CA}$ & 41965 & $x x x-x x x x$ & Johnathon Head & $12 / 27 / 2015$ & $B$ bottles & 3,100 & $\mathrm{C} 2$ & $287,483.13$ & \\
\hline 26 & 23 & Anna's Aromatherapy & WA & 41990 & $x x x-x x x x$ & Jerry & $12 / 28 / 2015$ & AA bottles & 4,500 & AF & $933,652.00$ & \\
\hline 27 & 24 & Kiddel Co. & GA & 42001 & $x x x-x x x x$ & Eddie Jones & $12 / 28 / 2015$ & AA bottles & 50,000 & $\mathrm{AF}$ & $8,152,858.95$ & \\
\hline 28 & 25 & Vat O Wine & WA & 42002 & $x x x-x x x x$ & Dale C. & $12 / 29 / 2015$ & $\mathrm{~F}$ bottles & 7,000 & B & $\mathrm{ABC}$ & \\
\hline 29 & 26 & Kiddel Co. & GA & 42010 & $x x x-x x x x$ & Eddie Jones & $12 / 29 / 2015$ & AA bottles & 50,000 & AF1 & $6,745,714.15$ & \\
\hline 30 & 27 & Mountain Water & $\mathrm{CO}$ & 42012 & $x x x-x x x x$ & William Stewart & $12 / 29 / 2015$ & $\mathrm{C}$ bottles & 50,000 & $\mathrm{C} 2$ & $6,144,758.61$ & \\
\hline 31 & 28 & & GA & 42013 & $x x x-x x x x$ & Eddie Jones & $12 / 29 / 2015$ & T bottles & 60,000 & $\mathrm{C} 2$ & $10,389,546.16$ & \\
\hline 32 & 29 & Mountain Water & $\mathrm{CO}$ & 42070 & $x x x-x x x x$ & William Stewart & $12 / 29 / 2015$ & $\mathrm{C}$ bottles & 30,000 & $\mathrm{C} 2$ & $3,456,784.42$ & \\
\hline 33 & 30 & Kiddel Co. & GA & 42075 & $x x x-x x x x$ & Eddie Jones & $12 / 30 / 2015$ & $\mathrm{C}$ bottles & 20,000 & $\mathrm{C} 2$ & $2,456,382.00$ & \\
\hline 34 & & & & & & & & & & & & \\
\hline 35 & & & & & & & & & Sun & Total: & $48,179,112.96$ & GL \\
\hline 36 & & & & & & & & & Total & per GL: & $50,724,160.96$ & \\
\hline
\end{tabular}




\section{Appendix B}

\section{Illustration of stimulus with areas of interest identified}

\begin{tabular}{|c|c|c|c|c|c|c|c|c|c|c|c|c|}
\hline \multicolumn{2}{|c|}{$\triangle \mathrm{A}$} & B & $\mathrm{C}$ & \multirow[t]{2}{*}{ D } & \multirow[t]{2}{*}{$E$} & $\mathrm{~F}$ & \multirow[t]{2}{*}{ G } & \multirow[t]{2}{*}{$\mathrm{H}$} & \multirow[t]{2}{*}{ I } & \multirow[t]{2}{*}{ J } & \multirow{2}{*}{\multicolumn{2}{|c|}{ PBC }} \\
\hline 1 & A/R & Balance as of: $12 / 31 / 20$ & 15 & & & & & & & & & \\
\hline \multicolumn{13}{|l|}{2} \\
\hline 3 & & Customer & State & $\begin{array}{l}\text { Invoice } \\
\text { Number }\end{array}$ & Phone & Contact & $\begin{array}{c}\text { Invoice } \\
\text { Date }\end{array}$ & Items & Number & Skew & $\begin{array}{l}\text { Invoice } \\
\text { Amount }\end{array}$ & \\
\hline 4 & 1 & Sinus Aide & VA & 41569 & $x x x-x x x x$ & J. Johnson & $9 / 27 / 2015$ & A bottles & 1,000 & $\mathrm{AF}$ & $45,767.90$ & \\
\hline 5 & 2 & Jay \& Jack's Auto Oil & DE & 41624 & $x x x-x x x x$ & Pete Barnell & $10 / 9 / 2015$ & AA bottles & 5,000 & AF1 & $247,694.30$ & \\
\hline 6 & 3 & Generic Cola Inc. & NY & 41687 & $x x x-x x x x$ & Ben Anderson & $10 / 18 / 2015$ & $\mathrm{C}$ bottles & 500 & $\mathrm{~F}$ & $6,264.85$ & \\
\hline 7 & 4 & Florida Juice Corp & $\mathrm{FL}$ & 41699 & $x x x-x x x x$ & Guy M. & $11 / 3 / 2015$ & $\mathrm{~F}$ bottles & 800 & B & $68,585.40$ & \\
\hline 8 & 5 & Mars Liquid Detergents & VA & 41700 & $x x x-x x x x$ & Bob Lynch & $11 / 6 / 2015$ & A bottles & 6,000 & $\mathrm{AF}$ & $385,948.00$ & \\
\hline 9 & 6 & Silver Springs & MD & 41711 & $x x x-x x x x$ & Sharon S. & $11 / 9 / 2015$ & A bottles & 4,500 & AF & $45,825.31$ & \\
\hline 10 & 7 & Penns Oil & TX & 41756 & $x x x-x x x x$ & Chandler Moore & $11 / 14 / 2015$ & $\mathrm{C}$ bottles & 6,100 & $\mathrm{~F}$ & $112,375.20$ & \\
\hline 11 & 8 & Jay \& Jack's Auto Oil & WA & 41764 & $x x x-x x x x$ & Sam Sparx & $11 / 17 / 2015$ & B bottles & 10,000 & $\mathrm{C} 2$ & $1,482,229.00$ & \\
\hline 12 & 9 & Petrol TX & $\mathrm{TX}$ & 41767 & $x x x-x x x x$ & Tom S. & $11 / 20 / 2015$ & $Z$ bottles & 10,000 & FB12 & $1,765,900.99$ & \\
\hline 13 & 10 & Penns Oil & TX & 41768 & $x x x-x x x x$ & Chandler Moore & $11 / 23 / 2015$ & $\mathrm{~T}$ bottles & 3,000 & $\mathrm{XX2}$ & $57,459.00$ & \\
\hline 14 & 11 & The Bath \& Body Shop & WA & 41786 & $x x x-x x x x$ & Jess Wyman & $11 / 28 / 2015$ & B bottles & 25,000 & $\mathrm{C} 2$ & $412,426.15$ & \\
\hline 15 & 12 & Fresh Squeezed & $\mathrm{FL}$ & 41788 & $x x x-x x x x$ & Andy Goodman & $12 / 1 / 2015$ & $\mathrm{~T}$ bottles & 2,000 & $X \times 2$ & $25,478.96$ & \\
\hline 16 & 13 & Olivier's Olive Oil & CA & 41811 & $x x x-x x x x$ & Rachel Horn & $12 / 4 / 2015$ & $\mathrm{~F}$ bottles & 1,500 & B & $12,339.37$ & \\
\hline 17 & 14 & CustomerColumn & TX & 41845 & $x x x-x x x x$ & Tom S. & $12 / 5 / 2015$ & $Z$ bottles & 30,000 & FB12 & 3765 an 00 & \\
\hline 18 & 15 & ErrorCustomer1 & TX & 41877 & $x x x-x x x x$ & Tom S. & $12 / 8 / 2015$ & $Z$ bottles & 25,000 & FB12 & $\begin{array}{l}\text { Invoicecolumn } 12 \\
2, I 8 U, \text { UUช. } 12\end{array}$ & \\
\hline 19 & 16 & Windox & $\mathrm{TN}$ & 41887 & $x x x-x x x x$ & Robert Hitchcock & $12 / 6 / 2015$ & AA bottles & 6,000 & AF1 & $311,411.42$ & \\
\hline 20 & 17 & Soup to Go & SC & 41888 & $x x x-x x x x$ & Cameron Baxter & $12 / 11 / 2015$ & A bottles & 2,000 & AF & $56,287.11$ & \\
\hline 21 & 18 & Liquid Chocolate & $\mathrm{CA}$ & 41889 & $x x x-x x x x$ & Toby Guan & $12 / 14 / 2015$ & F bottles & 8,000 & B & $89,541.50$ & \\
\hline 22 & 19 & Drinks R Us & $\mathrm{CA}$ & 41895 & $x x x-x x x x$ & Daniel Brown & ErrorDate 782 & B bottles & 6,000 & $\mathrm{~F}$ & $98,546.25$ & \\
\hline 23 & 20 & Alligator Aid & $\mathrm{FL}$ & 41900 & $x x x-x x x x$ & Aisha Phung & $12 / 18 / 2015$ & $Z$ bottles & 25 & FB12 & 261.71 & \\
\hline 24 & 21 & Pure Oil & $\mathrm{CA}$ & 41903 & $x x x-x x x x$ & Sarah Creighton & $12 / 20 / 2015$ & $\mathrm{C}$ bottles & 3,000 & $\mathrm{~F}$ & $298,475.00$ & \\
\hline 25 & 22 & Diet Water & $\mathrm{CA}$ & 41965 & $x x x-x x x x$ & Johnathon Head & $12 / 27 / 2015$ & $\mathrm{~B}$ bottles & 3,100 & $\mathrm{C} 2$ & $287,483.13$ & \\
\hline 26 & 23 & Anna's Aromatherapy & WA & 41990 & $x x x-x x x x$ & Jerry & $12 / 28 / 2015$ & AA bottles & 4,500 & AF & $933,652.00$ & \\
\hline 27 & 24 & Kiddel Co. & GA & 42001 & $x x x-x x x x$ & Eddie Jones & $12 / 28 / 2015$ & AA bottles & 50,000 & $\mathrm{AF}$ & $8,152,858.95$ & \\
\hline 28 & 25 & Vat O Wine & WA & 42002 & $x x x-x x x x$ & Dale C. & $12 / 29 / 2015$ & $\mathrm{~F}$ bottles & 7,000 & B & Errorlnvoice ABC & \\
\hline 29 & 26 & Kiddel Co. & GA & 42010 & $x x x-x x x x$ & Eddie Jones & $12 / 29 / 2015$ & AA bottles & 50,000 & AF1 & $6,745,714.15$ & \\
\hline 30 & 27 & Mountain Water & $\mathrm{CO}$ & 42012 & $x x x-x x x x$ & William Stewart & $12 / 29 / 2015$ & C bottles & 50,000 & $\mathrm{C} 2$ & $6,144,758.61$ & \\
\hline 31 & 28 & ErrorCustomer2 & GA & 42013 & $x x x-x x x x$ & Eddie Jones & $12 / 29 / 2015$ & $T$ bottles & 60,000 & $\mathrm{C} 2$ & $10,389,546.16$ & \\
\hline 32 & 29 & Mountain Water & $\mathrm{CO}$ & 42070 & $x x x-x x x x$ & William Stewart & $12 / 29 / 2015$ & C bottles & 30,000 & $\mathrm{C} 2$ & $3,456,784.42$ & \\
\hline 33 & 30 & Kiddel Co. & GA & 42075 & $x x x-x x x x$ & Eddie Jones & $12 / 30 / 2015$ & $\mathrm{C}$ bottles & 20,000 & $\mathrm{C} 2$ & $2,456,382.00$ & \\
\hline 34 & & & & & & & & & & & & \\
\hline 35 & & & & & & & & & & Total: & $48,179,112.96$ & GL \\
\hline 36 & & & & & & & & & Tota & er GL: & $50,724,160.96$ & \\
\hline
\end{tabular}




\section{References}

Alles, M., A. Kogan, and M. Vasarhelyi. 2008. Putting continuous auditing theory into practice: Lessons from two pilot implementations. Journal of Information 22 (2): 195-214, doi: 10.2308/jis.2008.22.2.195.

Alter, A. L., and D. M. Oppenheimer. 2009. Uniting the tribes of fluency to form a metacognitive nation. Personality and Social Psychology Review 13 (3): 219-235, doi: 10.1177/1088868309341564.

Alter, A. L., D. M. Oppenheimer, N. Epley, and R. N. Eyre. 2007. Overcoming intuition: Metacognitive difficulty activates analytic reasoning. Journal of Experimental Psychology: General 136: 569-576.

Andiola, L. M., T. A. Lambert, and E. J. Lynch. 2018. Sprandel, Inc.: Electronic workpapers, audit documentation, and closing review notes in the audit of accounts receivable. Issues in Accounting Education 33 (2): 43-55, doi: 10.2308/iace-52055.

Ashby, N. J., J. G. Johnson, I. Krajbich, and M. Wedel. 2016. Applications and innovations of eye-movement research in judgment and decision making. Journal of Behavioral Decision Making 29 (2-3): 96-102, doi: 10.1002/bdm.1956.

Backof, A. G., T. D. Carpenter, and J. Thayer. 2018. Auditing complex estimates: How do construal level and evidence formatting impact auditors' consideration of inconsistent evidence? Contemporary Accounting Research 35 (4): 1798-1815, doi: 10.1111/19113846.12368

Bennett, G. B., and R. C. Hatfield. 2013. The effect of the social mismatch between staff auditors and client management on the collection of audit evidence. The Accounting Review 88 (1): 31-50, doi: 10.2308/accr-50286.

Bonner, S. E. 2008. Judgment and decision making in accounting. Upper Saddle River, NJ: Prentice Hall.

Brandon, D. M., J. H. Long, T. M. Loraas, J. Mueller-Phillips, and B. Vansant. 2014. Online instrument delivery and participant recruitment services: Emerging opportunities for behavioral accounting research. Behavioral Research in Accounting 26 (1): 1-23, doi: 10.2308/bria-50651.

Brasel, K. R., R. C. Hatfield, E. B. Nickell, and L. M. Parsons. 2019. The effect of fraud risk assessment frequency and fraud inquiry timing on auditors' skeptical judgments and actions. Accounting Horizons 33 (1): 1-15, doi: 10.2308/accg-52349.

Brazel, J. F., S. B. Jackson, T. J. Schaefer, and B. W. Stewart. 2016. The outcome effect and professional skepticism. The Accounting Review 91 (6): 1577-1599, doi: 10.2308/accr-51448.

Brazel, J. F. J. Leiby, and T. J. Schaefer. 2018. Do rewards encourage professional skepticism? Working paper, North Carolina State University, University of Illinois Urbana-Champaign, and University of Missouri - Kansas City, https://papers.ssrn.com/sol3/papers.cfm?abstract_id=3111466.

Brennan, S. E., and M. Williams. 1995. The feeling of another's knowing: Prosody and filled pauses as cues to listeners about the metacognitive states of speakers. Journal of Memory and Language 34 (3): 383-398, doi: 10.1006/jmla.1995.1017. 
Brown-Liburd, H., H. Issa, and D. Lombardi. 2015. Behavioral implications of Big Data's impact on audit judgment and decision making and future research directions. Accounting Horizons 29 (2): 451-468, doi:10.2308/acch-51023.

Buckless, F. A., and S. P. Ravenscroft. 1990. Contrast coding: A refinement of ANOVA in behavioral analysis. The Accounting Review 65 (4): 933-945.

Casey, C. J. Jr. 1980. Variation in accounting information load: The effect on loan officers' prediction of bankruptcy. The Accounting Review 55 (1): 36-49.

Chen, Y., J. Jermias, and T. Panggabean. 2016. The role of visual attention in the managerial judgment of balanced-scorecard performance evaluation: Insights from using an eye-tracking device. Journal of Accounting Research 54 (1): 113-146, doi: 10.1111/1475-679X.12102.

Chewning, E. G. Jr., and A. M. Harrell. 1990. The effect of information load on decision makers' cue utilization levels and decision quality in a financial distress decision task. Accounting, Organizations and Society 15 (6): 527-542, doi: 10.1016/0361-3682(90)90033-Q.

Coram, P., J. Ng, and D. R. Woodliff. 2004. The effect of risk of misstatement on the propensity to commit reduced audit quality acts under time budget pressure. Auditing: A Journal of Practice \& Theory 23 (2): 159-167, doi: 10.2308/aud.2004.23.2.159.

Dalla Via, N., P. Perego, and M. van Rinsum. 2018. How accountability type influences information search processes and decision quality. Accounting, Organizations and Society (forthcoming), doi: 10.1016/j.aos.2018.10.001.

Deng, X., B. E. Kahn, H. R. Unnava, and H. Lee. 2016. A “wide” variety: Effects of horizontal versus vertical display on assortment processing, perceived variety, and choice. Journal of Marketing Research 53 (5): 682-698.

Dimoka, A., R. D. Banker, I. Benbasat, F. D. Davis, A. R. Dennis, D. Gefen, A. Gupta, A. Ischebeck, P. Kenning, P. A. Pavlou, G. Müller-Putz, R. Riedl, J. V. Brocke, and B. Weber. 2012. On the use of neurophysiological tools in IS research: Developing a research agenda for NeuroIS. MIS Quarterly 36 (3): 679-702.

Djamasbi, S. 2014. Eye tracking and web experience. AIS Transactions on Human-Computer Interaction 6 (2): 37-54.

Ehmke, C., and C. Wilson. 2007. Identifying web usability from eye tracking data. In Proceedings of the $21^{\text {st }}$ British HCI Group Annual Conference on HCI 2007: People and Computers XXI: HCI...but not as we know it. Vol. 1, 119-128. University of Lancaster, U. K.: The British Computer Society.

Eppler, M. J., and J. Mengis. 2003. A framework for information overload research in organizations: Insights from organization science, accounting, marketing, MIS, and related disciplines. The Information Society 20 (5): 324-344, doi: 10.1080/01972240490507974.

Fehrenbacher, D. D., A. K. Schulz, and K. Rotaru. 2018. The moderating role of decision mode in subjective performance evaluation. Management Accounting Research 41 (December): 110, doi: 10.1016/j.mar.2018.03.001.

Franzel, J. 2013. Auditor objectivity and skepticism - What's next? Presentation at the American Accounting Association Annual Meeting, Anaheim, CA, August 5, 2013. Available at: https://pcaobus.org/News/Speech/Pages/08052013_AAA.aspx (last accessed 08/28/2018). 
Fukukawa, H., and T. J. Mock. 2011. Audit risk assessments using belief versus probability. Auditing: A Journal of Practice \& Theory 30 (1): 75-99, doi: 10.2308/aud.2011.30.1.75.

Glöckner, A., S. Fiedler, G. Hochman, S. Ayal, and B. Hilbig. 2012. Processing differences between descriptions and experience: A comparative analysis using eye-tracking and physiological measures. Frontiers in Psychology 3: 1-15, doi: 10.3389/fpsyg.2012.00173.

Glover, S. M., and D. F. Prawitt. 2014. Enhancing auditor professional skepticism: The professional skepticism continuum. Current Issues in Auditing 8 (2): 1-10, doi: 10.2308/ciia50895.

Gramling, A. A., E. O’Donnell, and S. D. Vandervelde. 2010. Audit partner evaluation of compensating controls: A focus on design effectiveness and extent of auditor testing. Auditing: A Journal of Practice \& Theory 29 (2): 175-187, doi: 10.2308/aud.2010.29.2.175.

Griffith, E. E., K. Kadous, D. Young. 2016. How insights from the "new" JDM research can improve auditor judgment: Fundamental research questions and methodological advice. Auditing: A Journal of Practice \& Theory 35 (2): 1-22, doi: 10.2308/ajpt-51347.

Guggenmos, R. D., M. D. Piercey, and C. P. Agoglia. 2018. Custom contrast testing: Current trends and a new approach. The Accounting Review 93 (5): 233-244, doi: 10.2308/accr52005 .

Hackenbrack, K. 1992. Implications of seemingly irrelevant evidence in audit judgment. Journal of Accounting Research 30: 126-136, doi: 10.2307/2491095.

Hampton, C. 2015. Estimating and reporting structural equation models with behavioral accounting data. Behavioral Research in Accounting 27 (2): 1-34, doi: 10.2308/bria-51226.

Hansen, J., A. Dechêne, and M. Wänke. 2008. Discrepant fluency increases subjective truth. Journal of Experimental Social Psychology 44 (3): 687-691, doi: 10.1016/j.jesp.2007.04.005.

Hoffman, V. B., and J. M. Patton. 1997. Accountability, the dilution effect, and conservatism in auditors' fraud judgments. Journal of Accounting Research 35: 227-238, doi: $10.2307 / 2491362$.

Holmqvist, K., and R. Andersson. 2017. Eye Tracking: A Comprehensive Guide to Methods, Paradigms and Measures $2^{\text {nd }}$ Edition. Lund, Sweden: Lund Eye-Tracking Research Institute.

Holmqvist, K., M. Nyström, R. Andersson, R. Dewhurst, H. Jarodzka, and J. Van de Weijer. 2011. Eye Tracking: A Comprehensive Guide to Methods and Measures $1^{\text {st }}$ Edition. Oxford, United Kingdom: Oxford University Press.

Hurtt, R. K. 2010. Development of a scale to measure professional skepticism. Auditing: A Journal of Practice \& Theory 29 (1): 149-171, doi: 10.2308/aud.2010.29.1.149.

Hurtt, R. K., H., Brown-Liburd, C. E., Earley, and G. Krishnamoorthy. 2013. Research on auditor professional skepticism: Literature synthesis and opportunities for future research. Auditing: A Journal of Practice \& Theory 32 (Supplement 1): 45-97, doi: 10.2308/ajpt50361.

IFIAR (International Forum of Independent Audit Regulators). 2018. Survey of inspection findings. Available at: https://www.ifiar.org/?wpdmdl=7970 (last accessed 08/28/2018). 
Iselin, E. R. 1988. The effects of information load and information diversity on decision quality in a structured decision task. Accounting, Organizations and Society 13: 147-164, doi: 10.1016/0361-3682(88)90041-4.

Iselin, E. R. 1993. The effects of the information and data properties of financial ratios and statements on managerial decision quality. Journal of Business Finance \& Accounting 20: 249-267, doi: 10.1111/j.1468-5957.1993.tb00663.x.

Jacoby, J. 1984. Perspectives on information overload. Journal of Consumer Research 10 (4): 432-435, doi: 10.1086/208981.

Jacoby, L. L., and K. Whitehouse. 1989. An illusion of memory: False recognition influenced by unconscious perception. Journal of Experimental Psychology: General 118: 126-135, doi: 10.1037/0096-3445.118.2.126.

James, K. L. 2003. The effects of internal audit structure on perceived financial statement fraud prevention. Accounting Horizons 17 (4): 315-327, doi: 10.2308/acch.2003.17.4.315.

Johnston, W. A., V. J. Dark, and L. L. Jacoby. 1985. Processing fluency and recognition judgments. Journal of Experimental Psychology: Learning, Memory, and Cognition 11 (1): 311, doi: 10.1037/0278-7393.11.1.3.

Just, M. A., and P. A. Carpenter. 1980. A theory of reading: From eye fixations to comprehension. Psychological Review 87 (4): 329-354, doi: 10.1037/0033-295X.87.4.329.

Keller, K. L., and R. Staelin. 1987. Effects of quality and quantity of information on decision effectiveness. The Journal of Consumer Research 14: 200-213, doi: 10.1086/209106.

Kline, R. B. 2010. Principles and practice of structural equation modeling (3rd edition). New York, NY: Guilford Press.

KPMG. 2017. 2017 Transparency Report. KPMG International Cooperative. Available at: https://home.kpmg.com/xx/en/home/about/governance/transparency-report.html (last accessed: August 27, 2018).

Lambert, T. A., K. L. Jones, J. F. Brazel, and D. S. Showalter. 2017. Audit time pressure and earnings quality: An examination of accelerated filings. Accounting, Organizations and Society 58: 50-66, doi: 10.1016/j.aos.2017.03.003.

Lee, A. Y., and A. A. Labroo. 2004. The effect of conceptual and processing fluency on brand evaluation. Journal of Marketing Research 41 (2): 151-165, doi: 10.1509/jmkr.41.2.151.28665.

Long, J. H., and K. A. Basoglu. 2016. The impact of task interruption on tax accountants' professional judgment. Accounting, Organizations and Society 55: 96-113, doi: 10.1016/j.aos.2016.08.004.

Luippold, B. L., T. Kida, M. D. Piercey, and J. F. Smith. 2015. Managing audits to manage earnings: The impact of diversions on an auditor's detection of earnings management. Accounting, Organizations and Society 41: 39-54, doi: 10.1016/j.aos.2014.07.005.

Lynch, E. J., and L. M. Andiola. 2018. If eyes are the window to our soul, what role does eye tracking play in accounting research? Behavioral Research in Accounting (forthcoming), doi: $10.2308 /$ bria-52283. 
McGlone, M. S., and J. Tofighbakhsh. 2000. Birds of a feather flock conjointly (?): Rhyme as reason in aphorisms. Psychological Science 11 (5): 424-428, doi: 10.1111/1467-9280.00282.

Meißner, M., and J. Oll. 2019. The promise of eye-tracking methodology in organizational research: A taxonomy, review, and future avenues. Organizational Research Methods 22 (2): 590-617, doi: 10.1177/1094428117744882.

Murphy, K. R., R. A. Jako, and R. L. Anhalt. 1993. Nature and consequences of halo error: A critical analysis. Journal of Applied Psychology 78 (2): 218-225, doi: 10.1037/00219010.78.2.218.

Nelson, M. W. 2009. A model and literature review of professional skepticism in auditing. Auditing: A Journal of Practice \& Theory 28 (2): 1-34, doi: 10.2308/aud.2009.28.2.1.

Nelson, M. W., and H.-T. Tan. 2005. Judgment and decision making research in auditing: A task, person, and interpersonal interaction perspective. Auditing: A Journal of Practice \& Theory 24 (Supplement): 41-71, doi: 10.2308/aud.2005.24.s-1.41.

Nelson, M. W., and K. K. Rupar. 2015. Numerical formats within risk disclosures and the moderating effect of investors' concerns about management discretion. The Accounting Review 90 (3): 1149-1168, doi: 10.2308/accr-50916.

Nisbett, R. E., and T. D. Wilson. 1977. The halo effect: Evidence for unconscious alteration of judgments. Journal of Personality and Social Psychology 35 (4): 250-256, doi: 10.1037/0022-3514.35.4.250.

Nolder, C. J., and K. Kadous. 2018. Grounding the professional skepticism construct in mindset and attitude theory: A way forward. Accounting, Organizations and Society 67: 1-14, doi: 10.1016/j.aos.2018.03.010.

Novemsky, N., R. Dhar, N. Schwarz, and I. Simonson. 2007. Preference fluency and consumer choice. Journal of Marketing Research 44 (3): 347-356, doi: 10.1509/jmkr.44.3.347.

Olsen, A. 2012. Tobii I-VT fixation filter - Algorithm description. Tobii.com. Available at: https://www.tobiipro.com/siteassets/tobii-pro/learn-and-support/analyze/how-do-we-classifyeye-movements/tobii-pro-i-vt-fixation-filter.pdf.

Olsen, A., and R. Matos. 2012. Identifying parameter values for an I-VT fixation filter suitable for handling data sampled with various sampling frequencies. Proceedings of the Symposium on Eye Tracking Research and Applications, Santa Barbara, CA, March 28-30.

Orquin, J. L., and S. M. Loose. 2013. Attention and choice: A review on eye movements in decision making. Acta Psychologica 144 (1): 190-206, doi: 10.1016/j.actpsy.2013.06.003.

Payne, E. A. and R. J. Ramsay. 2005. Fraud risk assessments and auditors' professional skepticism. Managerial Auditing Journal 20 (3): 321-330, doi: 10.1108/02686900510585636.

PCAOB (Public Company Accounting Oversight Board). 2010. Audit Evidence. Auditing Standard No. 1105. Washington, D.C.: PCAOB.

PCAOB. 2012. Maintaining and Applying Professional Skepticism in Audits. Staff Audit Practice Alert No. 10. Washington, D.C.: PCAOB. 
Peytcheva, M. 2014. Professional skepticism and auditor cognitive performance in a hypothesistesting task. Managerial Auditing Journal 29 (1): 27-49, doi: 10.1108/MAJ-04-2013-0852.

Popova, V. 2013. Exploration of skepticism, client-specific experiences, and audit judgments. Managerial Auditing Journal 28 (2): 140-160, doi: 10.1108/02686901311284540.

Quadackers, L., T. Groot., and A. Wright. 2014. Auditors' professional skepticism: Neutrality versus presumptive doubt. Contemporary Accounting Research 31 (3): 639-657, doi: 10.1111/1911-3846.12052.

Rayner, K. 2009. Eye movements and attention in reading, scene perception, and visual search. The Quarterly Journal of Experimental Psychology 62 (8): 1457-1506, doi: 10.1080/17470210902816461.

Reber, R., and N. Schwarz. 1999. Effects of processing fluency on judgments of truth. Consciousness and Cognition 8: 338-342, doi: 10.1006/ccog.1999.0386.

Reber, R., P. Winkielman, and N. Schwarz. 1998. Effects of perceptual fluency on affective judgments. Psychological Science 9 (1): 45-48, doi: 10.1111/1467-9280.00008.

Reber, R., T. D. Zimmermann, and P. Wurtz. 2004. Judgments of duration, figure-ground contrast, and size for words and nonwords. Perception \& Psychophysics 66: 1105-1114, doi: 10.3758/BF03196839.

Rennekamp, K. 2012. Processing fluency and investors reactions to disclosure readability. Journal of Accounting Research 50 (5): 1319-1354, doi: 10.1111/j.1475679X.2012.00460.x.

Rennekamp, K. 2018. Cool ways to incorporate professional participants into our research. Presentation delivered at the 2018 Accounting, Organizations and Behavior Annual Conference, Phoenix, AZ, October 13, 2018.

Rose, A. M., J. M. Rose, K. Sanderson, and J. Thibodeau. 2017. When should audit firms introduce analyses of Big Data into the audit process. Journal of Information Systems 31 (3): 81-99, doi: 10.2308/isys-51837.

Roussey, J., and A. Piolat. 2008. Critical reading effort during text revision. European Journal of Cognitive Psychology 20 (4): 765-792, doi: 10.1080/09541440701696135.

Salvucci, D. D., and J. H. Goldberg. 2000. Identifying fixations and saccades in eye-tracking protocols. Proceedings of the 2000 Symposium on Eye Tracking Research and Applications, Palm Beach Gardens, FL, November 6-8.

Schick, A. G., L. A. Gorden, and S. Haka. 1990. Information overload: A temporal approach. Accounting Organizations and Society 15: 199-220, doi: 10.1016/0361-3682(90)90005-F.

Schneider, S. C. 1987. Information overload: Causes and consequences. Human Systems Management 7 (2): 143-153, doi: 10.3233/HSM-1987-7207.

Schwarz, N. 2004. Metacognitive experiences in consumer judgment and decision making. Journal of Consumer Psychology 14: 332-348, doi: 10.1207/s15327663jcp1404_2.

Schwarz N., H. Bless, F. Strack, G. Klumpp, H. Rittenauer-Schatka, and A. Simons. 1991. Ease of retrieval as information: Another look at the availability heuristic. Journal of Personality and Social Psychology 61: 195-202, doi: 10.1037/0022-3514.61.2.195. 
Shah, A., and D. Oppenheimer. 2007. Easy does it: The role of fluency in cue weighting. Judgment and Decision Making 2 (6): 371-379.

Simnett, R. 1996. The effect of information selection, information processing and task complexity on predictive accuracy of auditors. Accounting, Organizations and Society 21 (78): 699-719, doi: 10.1016/0361-3682(96)00006-2.

Sirois, L. P., J. Bédard, and P. Bera. 2018. The informational value of key audit matters in the auditor's report: Evidence from an eye-tracking study. Accounting Horizons 32 (2): 141-162, doi: 10.2308/acch-52047.

Skurnik, I., N. Schwarz, and P. Winkielman. 2000. Drawing inferences from feelings: The role of naive beliefs. In The message within: The role of subjective experience in social cognition and behavior, edited by H. Bless and J. P. Forgas, 162-175. Philadelphia, PA: Taylor \& Francis.

Stocks, M. H., and A. Harrell. 1995. The impact of an increase in accounting information level on the judgment quality of individuals and groups. Accounting, Organizations and Society 20 (7): 685-700, doi: 10.1016/0361-3682(95)00012-X.

Tobii AB. 2016. User's manual Tobii Studio Version 3.4.5. Available at: https://www.tobiipro.com/siteassets/tobii-pro/user-manuals/tobii-pro-studio-user-manual.pdf (last accessed: July 31, 2018).

Tversky, A., and D. Kahneman. 1973. Availability: A heuristic for judging frequency and probability. Cognitive Psychology 5: 207-232.

Unkelbach, C. 2007. Reversing the truth effect: Learning the interpretation of processing fluency in judgments of truth. Journal of Experimental Psychology: Learning, Memory, and Cognition 33 (1): 219-230, doi: 10.1037/0278-7393.33.1.219.

Whittlesea, B. W. A., L. L. Jacoby, and K. Girard. 1990. Illusions of immediate memory: Evidence of an attributional basis for feelings of familiarity and perceptual quality. Journal of Memory and Language 29: 716-732, doi: 10.1016/0749-596X(90)90045-2.

Winkielman, P., and J. T. Cacioppo. 2001. Mind at ease puts a smile on the face: Psychophysiological evidence that processing facilitation leads to positive affect. Journal of Personality and Social Psychology 81 (6): 989-1000, doi: 10.1037/0022-3514.81.6.989. 
Figure 1 Theoretical model of the relationship between features of client-prepared data files

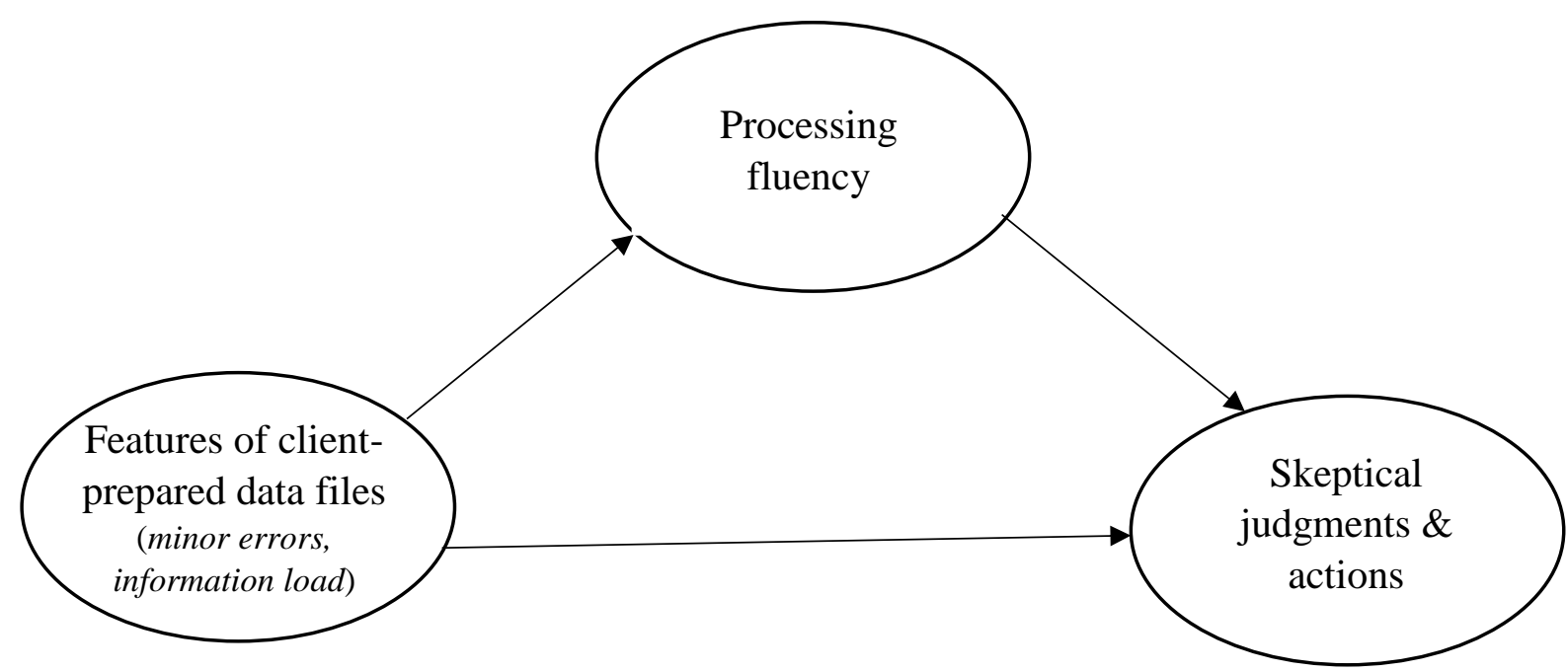

Notes: This figure illustrates the theoretical expectations of the relationships between features of client-prepared data files, processing fluency, and skeptical judgments and actions. 
Figure 2 Hypotheses $2 \mathrm{a}$ and $2 \mathrm{~b}$ predicted pattern of results

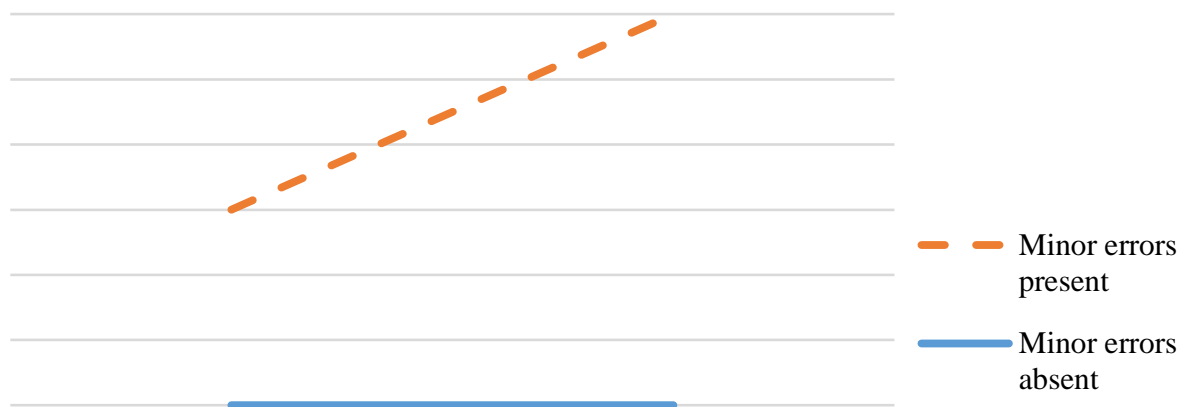

Low information load High information load

Notes: This figure illustrates our predicted interactions of the combination of minor errors and information load on disruptions in processing fluency (Hypothesis 2a) and skeptical judgments and actions (Hypothesis 2b). 
Figure 3 Path model of the effects of minor errors and information load on processing fluency and skeptical judgments and actions

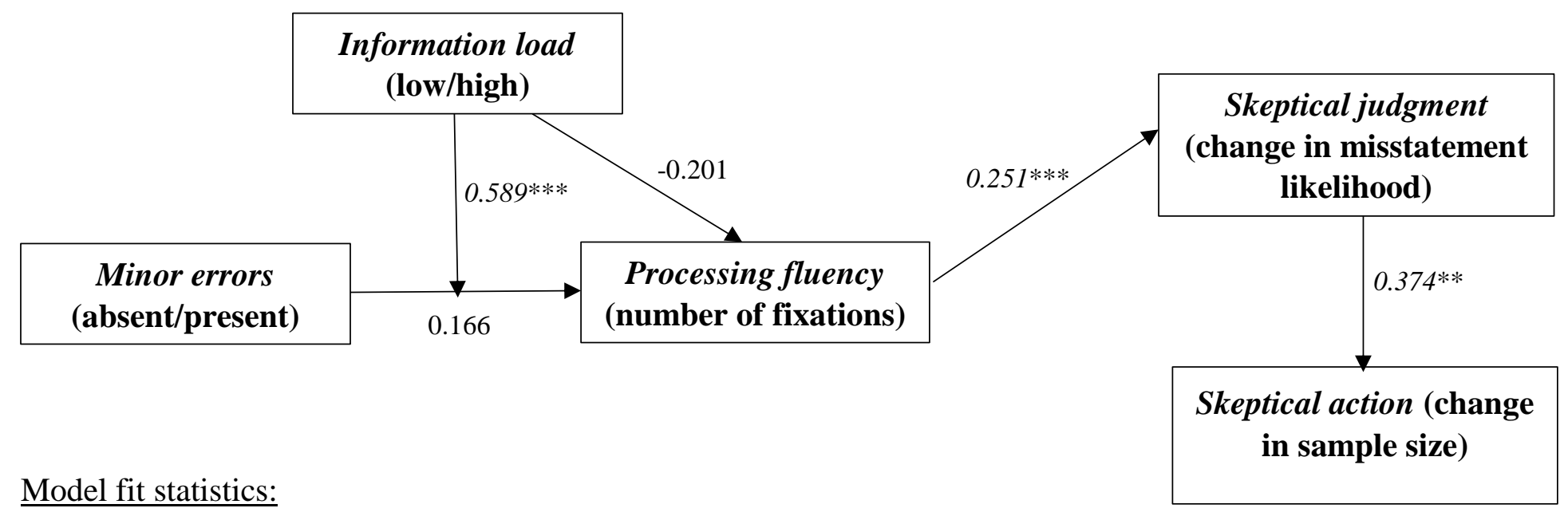

Comparative fit index $(\mathrm{CFI})=1.00$

Tucker-Lewis index $(\mathrm{TLI})=1.04$

RMSEA $=0.00$

Chi-square: $6.47, p$-value $=0.486$

SRMR: 0.08

Notes: Paths that are significant at $p<0.10,0.05$, and 0.01 are indicated by $* * *$, and $* * *$, respectively. We report one-tailed p-values for tests with directional predictions; these are in italics. For all other tests, we report two-tailed p-values. Error terms were included for processing fluency, skeptical judgment, and skeptical action because these measures are endogenous. 
TABLE 1

Eye tracking descriptive statistics

\begin{tabular}{|c|c|c|c|c|c|c|}
\hline Areas of interest (AOI) & \multicolumn{2}{|c|}{$\begin{array}{l}\text { Time to first fixation: } \\
\text { Mean in seconds (SD) }\end{array}$} & \multicolumn{2}{|c|}{$\begin{array}{l}\text { Number of fixations: } \\
\text { Mean counts (SD) }\end{array}$} & \multicolumn{2}{|c|}{$\begin{array}{l}\text { Total visit duration: } \\
\text { Mean in seconds (SD) }\end{array}$} \\
\hline Low information load & $\begin{array}{l}\text { Minor } \\
\text { errors } \\
\text { absent }\end{array}$ & $\begin{array}{c}\text { Minor } \\
\text { errors } \\
\text { present }\end{array}$ & $\begin{array}{l}\text { Minor } \\
\text { errors } \\
\text { absent }\end{array}$ & $\begin{array}{c}\text { Minor } \\
\text { errors } \\
\text { present }\end{array}$ & $\begin{array}{l}\text { Minor } \\
\text { errors } \\
\text { absent }\end{array}$ & $\begin{array}{c}\text { Minor } \\
\text { errors } \\
\text { present }\end{array}$ \\
\hline Customer column & $\begin{array}{c}3.80 \\
(7.55)\end{array}$ & $\begin{array}{c}1.47 \\
(2.43)\end{array}$ & $\begin{array}{l}26.67 \\
(22.58)\end{array}$ & $\begin{array}{c}32.57 \\
(17.61)\end{array}$ & $\begin{array}{c}7.13 \\
(6.66)\end{array}$ & $\begin{array}{c}8.57 \\
(4.77)\end{array}$ \\
\hline Invoice amount column & $\begin{array}{c}4.67 \\
(3.49)\end{array}$ & $\begin{array}{l}3.36 \\
(1.27)\end{array}$ & $\begin{array}{l}29.11 \\
(23.39)\end{array}$ & $\begin{array}{l}45.43 \\
(24.26)\end{array}$ & $\begin{array}{c}9.99 \\
(11.23)\end{array}$ & $\begin{array}{l}13.09 \\
(8.28)\end{array}$ \\
\hline Totals area & $\begin{array}{l}8.14^{*} \\
(6.82)\end{array}$ & $\begin{array}{l}2.46^{*} \\
(1.38)\end{array}$ & $\begin{array}{c}9.67 \\
(8.12)\end{array}$ & $\begin{array}{c}9.57 \\
(6.53)\end{array}$ & $\begin{array}{l}2.17 \\
(1.99)\end{array}$ & $\begin{array}{c}2.24 \\
(1.71)\end{array}$ \\
\hline Overall data file & - & & $\begin{array}{l}109.89 \\
(74.63)\end{array}$ & $\begin{array}{l}145.29 \\
(96.56)\end{array}$ & $\begin{array}{c}48.41 \\
(45.47)\end{array}$ & $\begin{array}{c}53.32 \\
(32.92)\end{array}$ \\
\hline $\begin{array}{l}\text { Error areas } \\
\text { (four areas combined) }\end{array}$ & & $\begin{array}{l}13.54 \\
(8.97) \\
\end{array}$ & & $\begin{array}{r}8.00 \\
(6.51) \\
\end{array}$ & & $\begin{array}{c}1.50 \\
(1.68) \\
\end{array}$ \\
\hline High information load & & & & & & \\
\hline Customer column & $\begin{array}{r}10.76^{*} \\
(11.62)\end{array}$ & $\begin{array}{l}2.42^{*} \\
(3.36)\end{array}$ & $\begin{array}{l}11.90 * * \\
(14.11)\end{array}$ & $\begin{array}{l}42.82 * * \\
(23.27)\end{array}$ & $\begin{array}{l}2.98 * * \\
(3.20)\end{array}$ & $\begin{array}{l}12.70 * * \\
(8.55)\end{array}$ \\
\hline Invoice amount column & $\begin{array}{c}20.64 \\
(27.59)\end{array}$ & $\begin{array}{c}21.59 \\
(27.49)\end{array}$ & $\begin{array}{l}13.10 * * \\
(11.51)\end{array}$ & $\begin{array}{l}35.36 * * \\
(24.65)\end{array}$ & $\begin{array}{c}3.96^{*} \\
(4.23)\end{array}$ & $\begin{array}{l}10.65^{*} \\
(8.29)\end{array}$ \\
\hline Totals area & $\begin{array}{c}23.60 \\
(33.69)\end{array}$ & $\begin{array}{c}25.11 \\
(38.20)\end{array}$ & $\begin{array}{l}4.10^{* *} \\
(5.11)\end{array}$ & $\begin{array}{l}11.27 * * \\
(6.03)\end{array}$ & $\begin{array}{l}0.91 * * \\
(1.34)\end{array}$ & $\begin{array}{l}2.66^{* *} \\
(1.45)\end{array}$ \\
\hline Overall data file & - & - & $\begin{array}{l}66.50 * * \\
(3198)\end{array}$ & $\begin{array}{l}239.35 * * \\
(118.70)\end{array}$ & $\begin{array}{l}40.20 * \\
(47.47)\end{array}$ & $82.71 *$ \\
\hline $\begin{array}{l}\text { Error areas } \\
\text { (four areas combined) }\end{array}$ & & $\begin{array}{c}21.40 \\
(12.48)\end{array}$ & & $\begin{array}{l}10.82 \\
(6.15)\end{array}$ & & $\begin{array}{c}2.65 \\
(1.99)\end{array}$ \\
\hline
\end{tabular}

Notes: This table provides the descriptive statistics captured by the eye-tracking equipment including, time-to-first fixation, number of fixations and total visit duration for each AOI. * and $* *$ indicate significance at $p<0.05$ and $p<$ 0.01 , respectively, between the minor errors absent and minor errors present conditions. 
TABLE 2

Experiment 1 - Results for processing fluency (number of fixations)

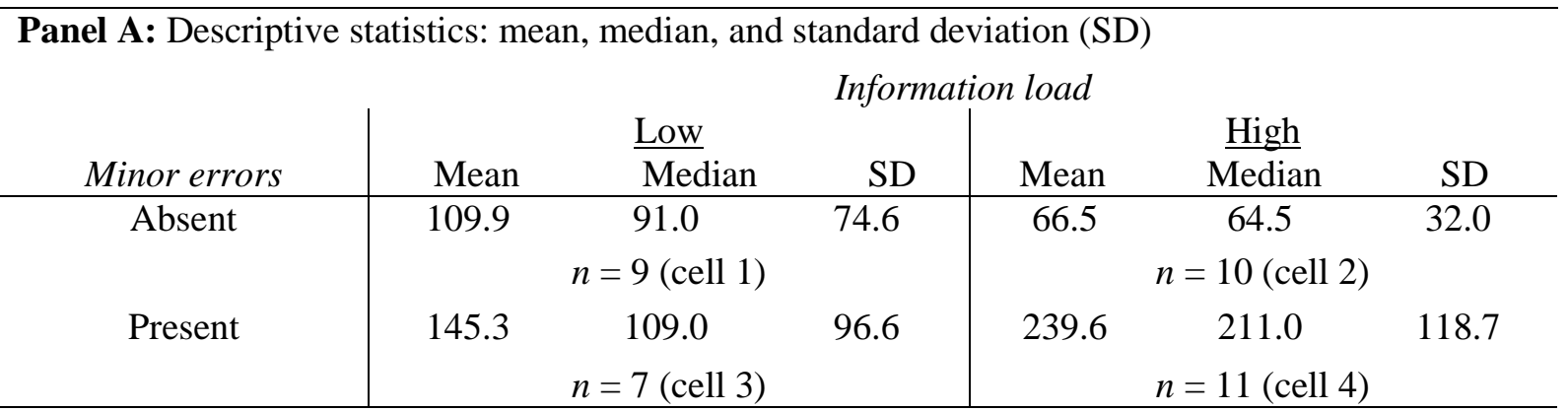

Panel B: Graphical representation of results

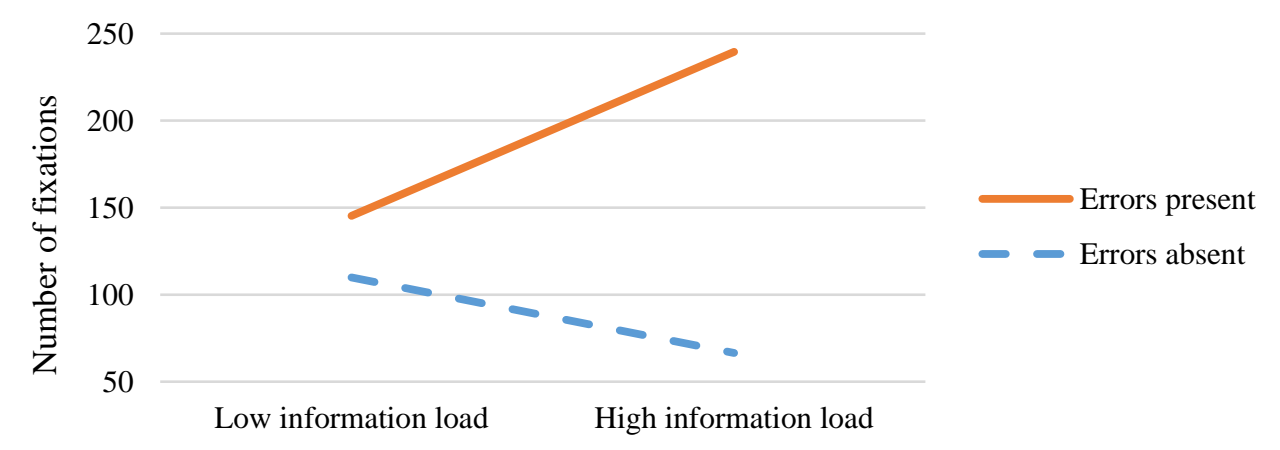

\begin{tabular}{|c|c|c|c|c|c|}
\hline $\begin{array}{l}\text { Panel C: Analysis of variance re } \\
\text { Source of variation }\end{array}$ & \multicolumn{5}{|c|}{ Panel C: Analysis of variance results } \\
\hline Minor errors & 97,663 & 1 & 97,663 & 12.86 & 0.001 \\
\hline Information load & 5,817 & 1 & 5,817 & 0.77 & 0.388 \\
\hline Minor errors $*$ information load & 42,590 & 1 & 42,590 & 5.61 & 0.024 \\
\hline Error & 53,036 & 93 & 570 & & \\
\hline \multicolumn{6}{|c|}{ Panel D: Contrast-coded analysis of variance results } \\
\hline Source of variation & S.S. & $\mathrm{df}$ & M.S. & F-statistic & $p$-value \\
\hline $\begin{array}{l}\text { Minor errors at low information } \\
\text { load < minor errors at high } \\
\text { information load }(-2,-2,+1,+3)\end{array}$ & 144,708 & 1 & 144,708 & 19.06 & $<0.001$ \\
\hline Residual & 26,243 & 2 & 13,122 & 1.73 & 0.193 \\
\hline Error & 250,592 & 33 & 7,594 & & \\
\hline \multicolumn{2}{|c|}{ Panel E: Simple effects tests comparisons } & $\mathrm{df}$ & t-statistic & p-value & \\
\hline \multicolumn{2}{|c|}{$\begin{array}{l}\text { Effect of information load given minor errors } \\
\text { present* }\end{array}$} & 33 & -2.251 & 0.016 & \\
\hline \multicolumn{2}{|c|}{$\begin{array}{l}\text { Effect of information load given minor errors } \\
\text { absent }\end{array}$} & 33 & -1.090 & 0.284 & \\
\hline \multicolumn{2}{|c|}{ Effect of errors given low information load* } & 33 & -0.081 & 0.212 & \\
\hline \multicolumn{2}{|c|}{ Effect of errors given high information load* } & 33 & -4.573 & $<0.001$ & \\
\hline
\end{tabular}

Notes: This table presents descriptive statistics, a graphical representation, results of the ANOVA, contrast-coded ANOVA, and simple effects tests for participants' level of processing fluency based on the total number of fixations on the client-prepared data file. For the contrast testing reported in panel $\mathrm{D}$, the cells of the experiment receive weights for minor errors/information load treatments as follows: absent/low $=-2$, absent/high $=-2$, present/low $=+1$, present/high $=+3$. $*$ indicates one-tailed $p$-value, consistent with our directional predictions. 
TABLE 3

Experiment 2 - Results for skeptical judgment (change in misstatement likelihood)

\begin{tabular}{|c|c|c|c|c|c|c|}
\hline \multicolumn{7}{|c|}{ Panel A: Descriptive statistics: mean, median, and standard deviation (SD) } \\
\hline Minor errors & Mean & $\frac{\text { Low }}{\text { Median }}$ & SD & Mean & $\frac{\text { High }}{\text { Median }}$ & SD \\
\hline Absent & 16.5 & $\begin{aligned} & 12.0 \\
= & 23(\mathrm{cel} l\end{aligned}$ & 15.9 & 23.0 & $\begin{aligned} & 24.5 \\
= & 24 \text { (cell }\end{aligned}$ & 21.8 \\
\hline Present & 26.9 & $\begin{array}{c}19.0 \\
=29(\mathrm{cell})\end{array}$ & 26.8 & 35.1 & $\begin{array}{c}30.0 \\
=21(\mathrm{cell}\end{array}$ & 28.6 \\
\hline
\end{tabular}

Panel B: Graphical representation of results

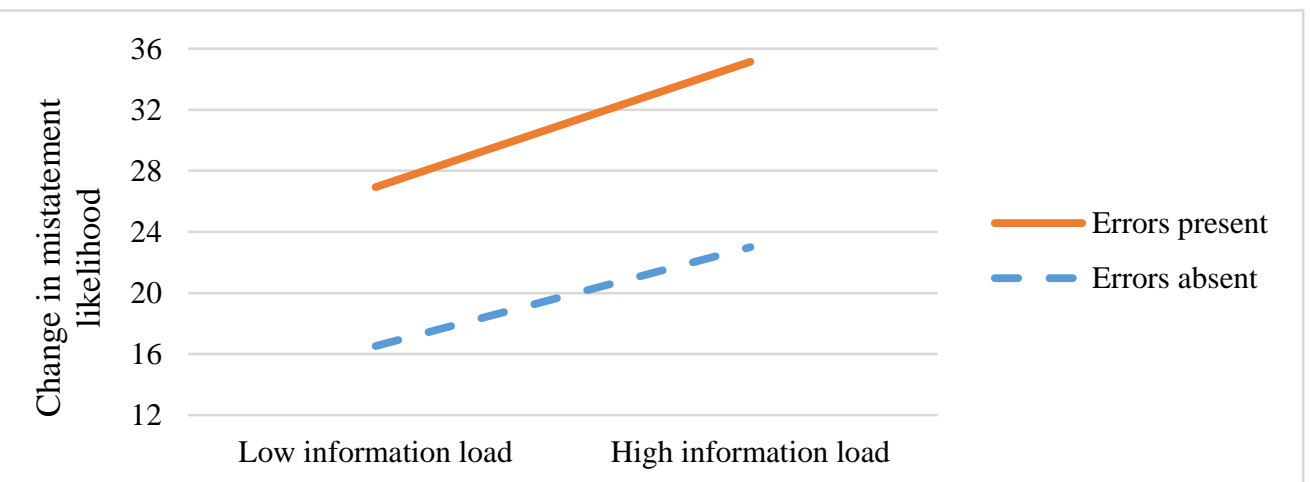

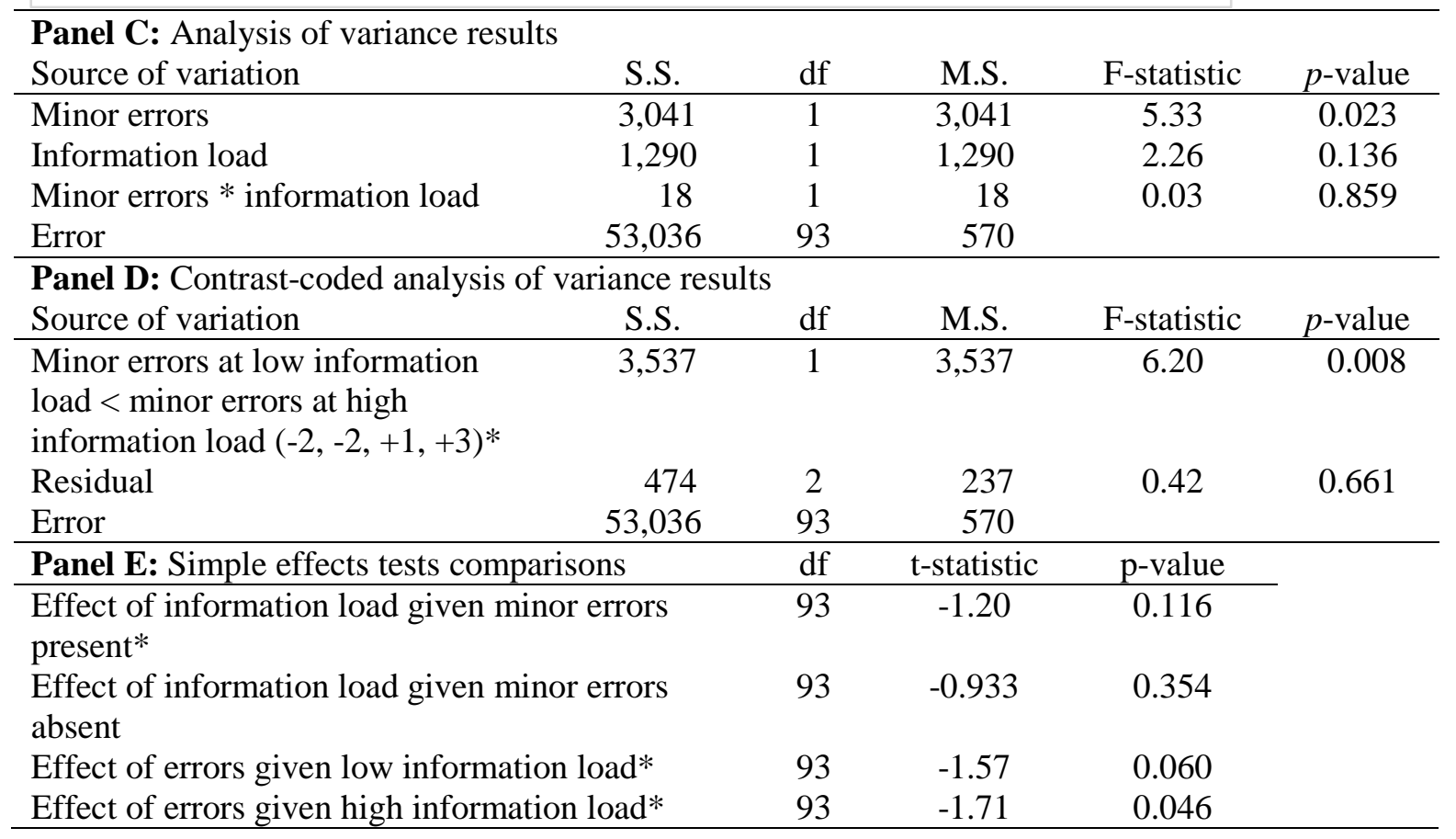

Notes: This table presents descriptive statistics, a graphical representation, results of the ANOVA, contrast-coded ANOVA, and simple effects tests for participants' level of skeptical judgment based on the change in misstatement likelihood assessed by participants. The change is calculated as the difference between the initial provided likelihood of 20 percent and participants' assessment after reviewing the client data file (assessed on a 0 to 30 item scale). For the contrast testing reported in panel D, the cells of the experiment receive weights for minor errors/information load treatments as follows: absent/low $=-2$, absent/high $=-2$, present $/$ low $=+1$, present $/$ high $=+3$. * indicates one-tailed $p$-value, consistent with our directional predictions. 
TABLE 4

Experiment 2 - Results for skeptical action (change in sample size)

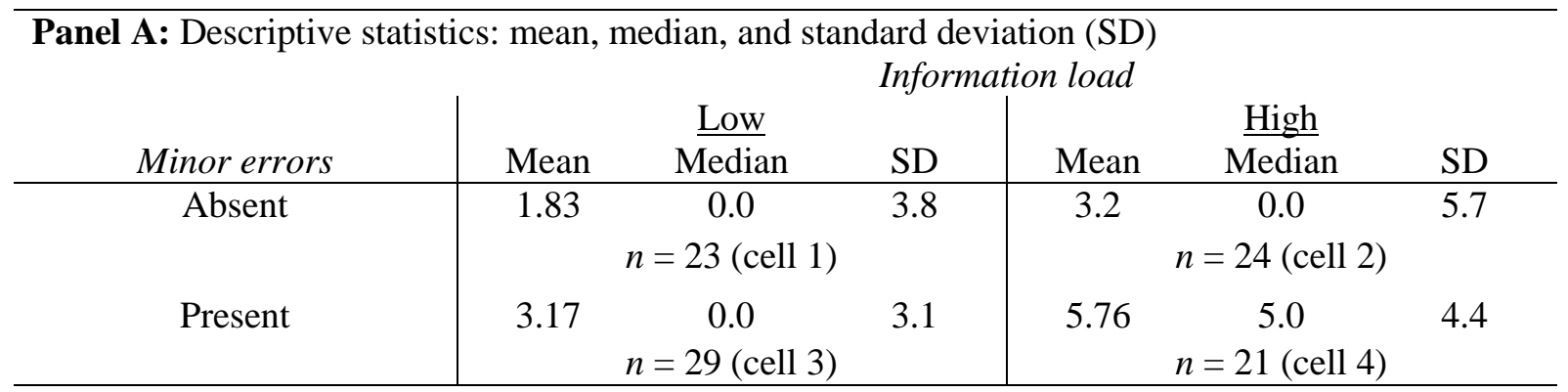

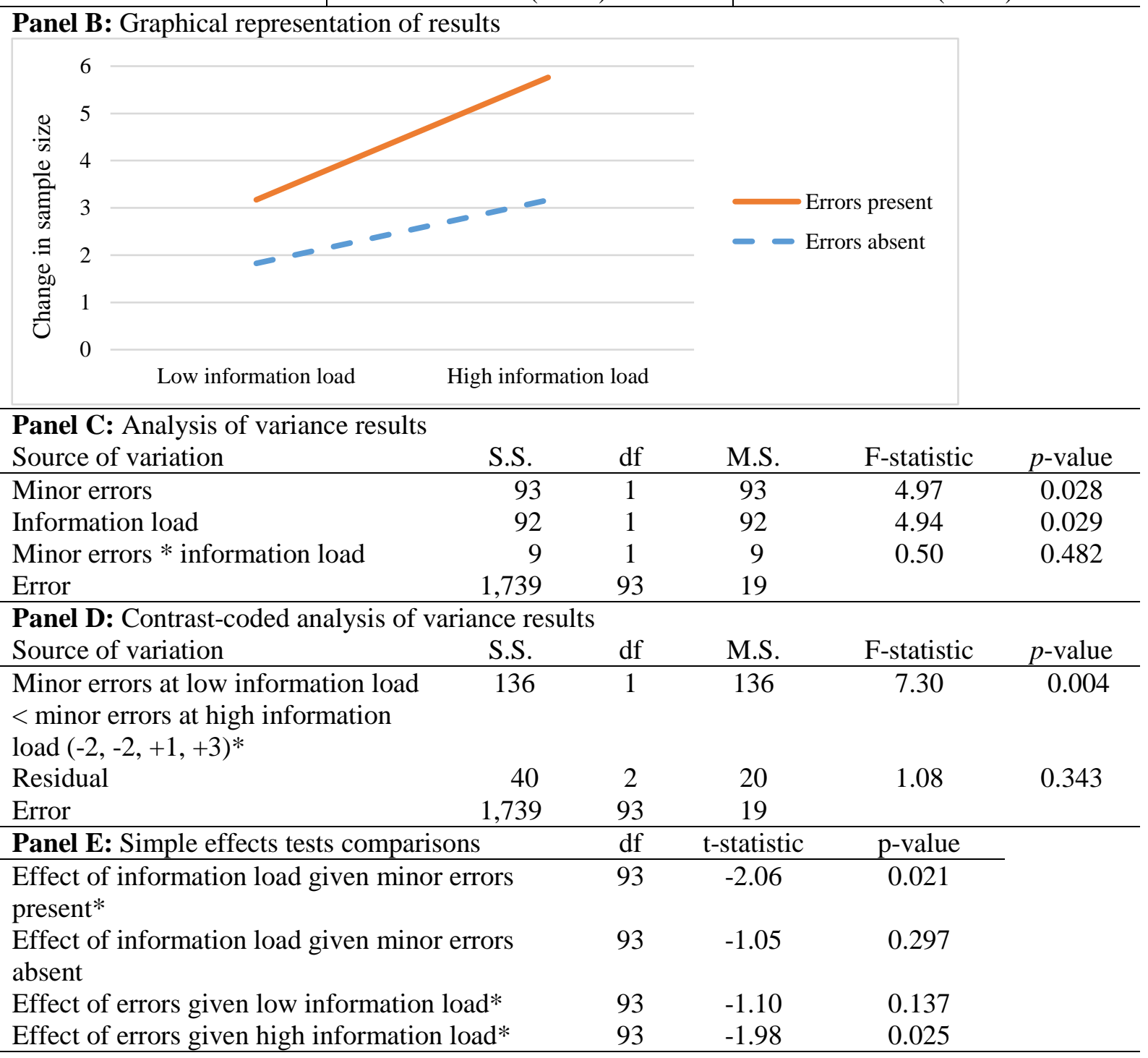

Notes: This table presents descriptive statistics, a graphical representation, results of the ANOVA, contrast-coded ANOVA, and simple effects tests for participants' level of skeptical action based on the change in planned sample size assessed by participants. The change is calculated as the difference between the prior year's sample size of ten items and participants' assessment of the sample size after reviewing the client data file (assessed on a 0 to 100 percent scale). For the contrast testing reported in panel $\mathrm{D}$, the cells of the experiment receive weights for minor errors/information load treatments as follows: absent/low $=-2$, absent/high $=-2$, present $/$ low $=+1$, present $/$ high $=+3$. $*$ indicates one-tailed $p$-value, consistent with our directional predictions. 